\title{
Physiology and Development: Why the West is Taller than the Rest
}

\author{
Carl-Johan Dalgaard ${ }^{\dagger}$ and Holger Strulik**
}

October 2014

\begin{abstract}
We hypothesize that the timing of the fertility transition is an important determinant of comparative physiological development. In support, we provide a model of long-run growth that elucidates the links between population size, average body size and income during development. Industrialization is shown to be accompanied by a reduction in family size and an intensification of nutrition per child. Early transition countries are therefore expected to be more developed today, economically and physiologically. Empirically, the timing of the fertility transition is strongly correlated with average body size across countries.
\end{abstract}

Keywords: unified growth theory, body size, fertility, nutrition. JEL: O11, I12, J13.

\footnotetext{
*We would like to thank Sam Bowles, Oded Galor, Nippe Lagerlöf, Ola Olsson, Fidel Perez Sebastian, Josh Wilde and seminar participants at a number of conferences and workshops for helpful comments.

$\dagger$ Department of Economics, University of Copenhagen and CEPR. Correspondence: Øster Farimagsgade 5, building 26, DK-1353 Copenhagen, Denmark; email: carl.johan.dalgaard@econ.ku.dk.

** Department of Economics, University of Goettingen. Correspondence: Platz der Goettinger Sieben 3, 37073 Goettingen, Germany; email: holger.strulik@wiwi.uni-goettingen.de
} 


\section{INTRODUCTION}

Average body size varies to a remarkable extend across the world. As Figure 1 documents, body size measured by average height varies by as much as $20 \mathrm{~cm}$ across countries, with the tallest individuals being located in Western Europe. How did these differences come about? Why are the tallest individuals located in the West? These questions are important as stature impacts on income, longevity as well as educational outcomes (e.g., Fogel, 1994; Schultz, 2002; Case and Paxon, 2008; Case et al., 2009; Cinnirella et al., 2011). Put differently, stature appears to influence all of the most commonly used markers of "human development" (Anand and Sen, 1997). In fact, even self-reported happiness appears positively correlated with height (Deaton and Aurora, 2009; Carrieri and Paola, 2012). The present paper advances a theory of how the observed differences in body size emerged during development.

Specifically, this study proposes a theory of long-run growth, where body size evolves endogenously. More specifically, the proposed theory suggests that during early phases of development, episodes of technological change led to only minute changes in body size, and living standards, but worked to increase population density. ${ }^{1}$ Eventually, however, unbalanced technological change between agriculture and non-agriculture led to rising relative prices of provisions, triggering a reduction in family size and rising nutritional spending per child. This change in the allocation of household resources, away from the quantity of children towards greater quality (in the sense of nutritional intake), enabled a process of rapid growth to occur; a process usually referred to as the take-off into sustained growth. Moreover, the pervasive rise in human body size, which has been observed across countries from the onset of the transition until today, arose as a consequence of an intensification of nutritional investments in children. By extension, in countries were the fertility transition occurred earlier one would expect to see taller citizens today.

In support of the theory we develop a two sector OLG model within which physiological development can be studied alongside fertility and the evolution of prosperity. Utility of adults is increasing in three arguments: the amount of nutrition they can offer to their children, the number of offspring, and (parental) consumption of non-food goods. These preferences are assumed to fulfill a "hierarchy of needs" principle: in a time of crisis parents will smooth

\footnotetext{
${ }^{1}$ See Kunitz (1987) and Koepke and Baten (2005) on the historical constancy of body size in Europe over the two millennia leading up to the demographic transition. See Ashraf and Galor (2011) on evidence regarding living standards and population density over the same period.
} 
Figure 1: Global Height Distribution: Females born ca. 1980

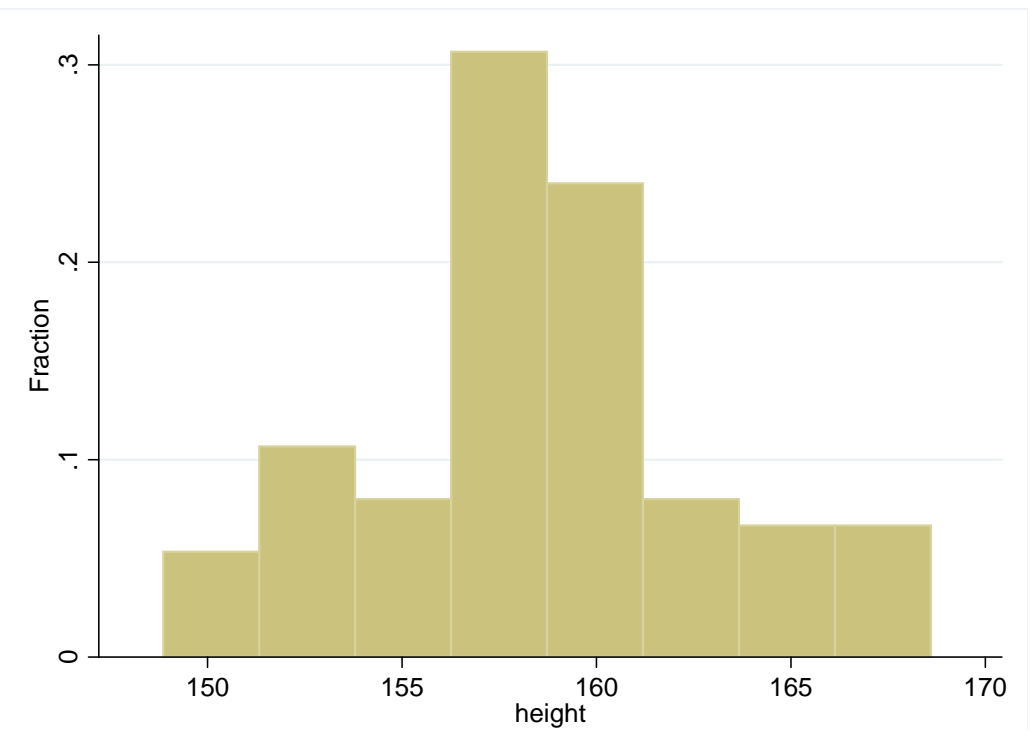

The figure shows a histogram for female body height, 75 countries. Sources: See Data Appendix

the consumption of their offspring more strongly than their family size, and family size more strongly than the consumption of non-food goods. ${ }^{2}$ Moreover, parents are assumed to cover their "subsistence needs", understood as their basal metabolic rate. Subsistence consumption is endogenous and depends on body size of the parent (predetermined at the time of optimization) as well as on fertility. ${ }^{3}$ Finally, better nutrition during childhood increases adult body size.

In a two sector economy, in which productivity growth is sector specific and due to learningby-doing, the "hierarchy of needs" principle, along with the physiological elements, has three important implications for the mechanics of development. First, fertility is declining in the relative price of food. This captures Malthus' "preventive check hypothesis": the tendency for fertility to be negatively associated with the relative price of provisions. Second, nutrition per child is increasing in the price of food. Third, "Engel's law" holds, whereby the consumption of food as a fraction of total expenditure declines (and consumption of non-food goods increases) with income. These elements combine so as to create a development trajectory capturing four

\footnotetext{
${ }^{2}$ The notion of a hierarchy of needs goes back to the work of Maslow (1943) and is supported by evidence in psychology, as well as micro studies on household behavior in times of crises, as detailed below.

${ }^{3}$ These assumptions are supported by evidence from biology and the nutrition sciences. Indeed the mappings from fertility and body size to basal metabolism (i.e., "subsistence consumption") can be given strong micro foundations all the way down to functional forms and associated parameter values.
} 
major transitions in human history: the take-off in income; the fertility transition; industrialization and a physiological transition whereby average body size first declines and eventually rises secularly.

The individual elements interact in the following way. During early stages of development most of the population is preoccupied with food procurement; i.e., employment is mainly in agriculture. As a result, productivity growth is faster within agriculture than outside agriculture. The relative price of agricultural goods is thus declining, favoring investments in the quantity of children by parents. Rising fertility raises overall productivity growth, due to the positive influence of population growth on learning-by-doing generated knowledge. While fertility thus is increasing, quality investments are modest, leading to a (weakly) declining body size of the representative individual. However, as a consequence of Engel's law and productivity growth in both sectors, employment is gradually being shifted towards non-food activities. Eventually, productivity growth in the non-agricultural sector exceeds that of agriculture. As a result, the relative price of agricultural goods begins to rise. This shifts the balance between quantity and quality investments at the level of the household; parents respond to the changing relative prices by investing more heavily in quality, and less in the quantity of children. Correspondingly, average body size rises, whereas fertility declines. Hence, while fertility overall follows an inverse U-shaped path, the path for body size is U-shaped. The gradual acceleration of technological progress, and declining fertility allows income per capita growth to take off. Accordingly, the present theory can account for four major transitions: the demographic transition; the take-off in living standards; the secular shift in employment out of agriculture, and the take-off in body size.

Using a calibrated version of the model we demonstrate that it is broadly consistent with the historical evolution of fertility and body size during the English industrial revolution. In particular, the causes of the puzzling $U$-shaped path for body size during industrialization have long been debated in the anthropometric economic history literature (see e.g., Komlos, 1993, 1998). The puzzle is why average body size seems to decline during a period featuring rising income per capita. Our model delivers the observed outcome. The basic intuition is that households in our model face a quantity-quality trade-off, involving family size and nutrition. Hence, the path of body size is essentially a mirror image of the path of fertility, which in England follows the familiar hump-shaped trajectory (e.g. Wrigley and Schofield, 1989). In addition, the 
model is qualitatively consistent with observed changes in income per capita, relative prices and the structure of the economy in the context of the industrial revolution in England (see Strulik and Weisdorf (2008) for evidence in these dimensions).

With the model in hand we proceed to investigate the causes of comparative differences in physiological development. Using the calibrated model we perturb initial conditions so as to produce "counterfactual" dates for the fertility transition. For each simulated transition we record the predicted body size as of the year 2000. This exercise reveals that the model is fairly effective in capturing the currently observed variation in body size across Europe, given realistic variation in transition dates, and that it predicts a positive influence from time since the fertility transition on current body size.

We subsequently explore whether the timing of the fertility transition more generally seems significantly correlated with current body size in a cross-section of countries, in the manner predicted by the theory. Consistent with the theory, our regression analysis reveals that countries that relatively early ventured through the fertility transition are inhabited by (on average) bigger individuals today. This correlation is robust to rigorous control for geographic confounders as well as income per capita and mortality during childhood. Our regression results suggests that the differentiated timing of the fertility transition can account for somewhere between $13 \%$ and $30 \%$ of international differences in body size.

In the present research we focus on the nutrition channel behind contemporary height differences. At the same time it is well known that some of the differences observed across countries in average body size (and shape) likely have a genetic origin (e.g., Ruff, 2002). The model developed below features deep physiological parameters, which might well have been influenced by evolutionary pressure and theoretically turn out to influence long-run body size. In practise, therefore, both genetic selection and the take-off mechanism have probably helped shape the global distribution of body size. We return to this issue in the context of the empirical testing of the theory below.

The present research is related to the literature on growth in the very long-run (see Galor, 2005, for a survey). At the mechanical level the present paper is most closely related to the study by Dalgaard and Strulik (2015), which examines the pre take-off dynamics of body size and population size, and the work of Strulik and Weisdorf (2008), which develops a unified growth theory of the take-off, accounting for the fertility transition, the growth acceleration 
and structural change. The value-added of the present research lies in providing an account for physiological development, before, during and after the take-off in income per capita, and in gauging the importance of the differentiated timing of the take-off in economic growth for comparative differences in body size.

The work of Weir (1993) should also be singled out, since Weir conceptualizes a size-number trade-off akin to the one formalized below, and uses it to explain the French fertility transition. More generally, the present research is related to a large anthropometric economic history literature (see Steckel, 2009, for a survey). This literature is rich on hypothesis' regarding the forces that shaped the path of body size before, during and after Industrialization. We acknowledge that there are many forces that may have shaped the path of body size, aside from the mechanisms highlighted here. The question is whether such alternative accounts are simultaneously reconcilable with the other fundamental transitions that occurred around the same time, involving output growth, fertility and a changing sector composition of output and employment. The present paper demonstrates that a mechanism involving relative food prices, in the presence of a size-number quantity-quality trade-off, can be.

The paper proceeds as follows. The next section discusses the empirical case in favor of a critical element of the model developed below: a trade-off involving fertility and average body size. Section 3 then develops the model, assuming a parametrically fixed level of technology. In Section 4 we add endogenous technological change and study the implied long-run development trajectory. Moreover, Section 4 also studies the ability of the model to account for stylized facts with regard to fertility, body size and more, in the context of the English Industrial Revolution. Section 5 studies comparative physiological development, by way of numerical experiments and regression analysis. Finally, section 6 concludes.

\section{The SIZE-NUMBER TRADE-OFF}

2.1. Existing evidence. Convincing evidence in favor of a quantity-quality trade-off is found in biology. At the level of the individual mammalian species, the inverse association between body size and rate of reproduction is by now well documented (Charnov and Ernest, 2006; Walker et al., 2008). Indeed, experimental studies manipulating offspring number or environment exist, which document the trade-off (Ruff, 2002). 
Figure 2: Crude Birth Rate and Average Height 1745-1960: England

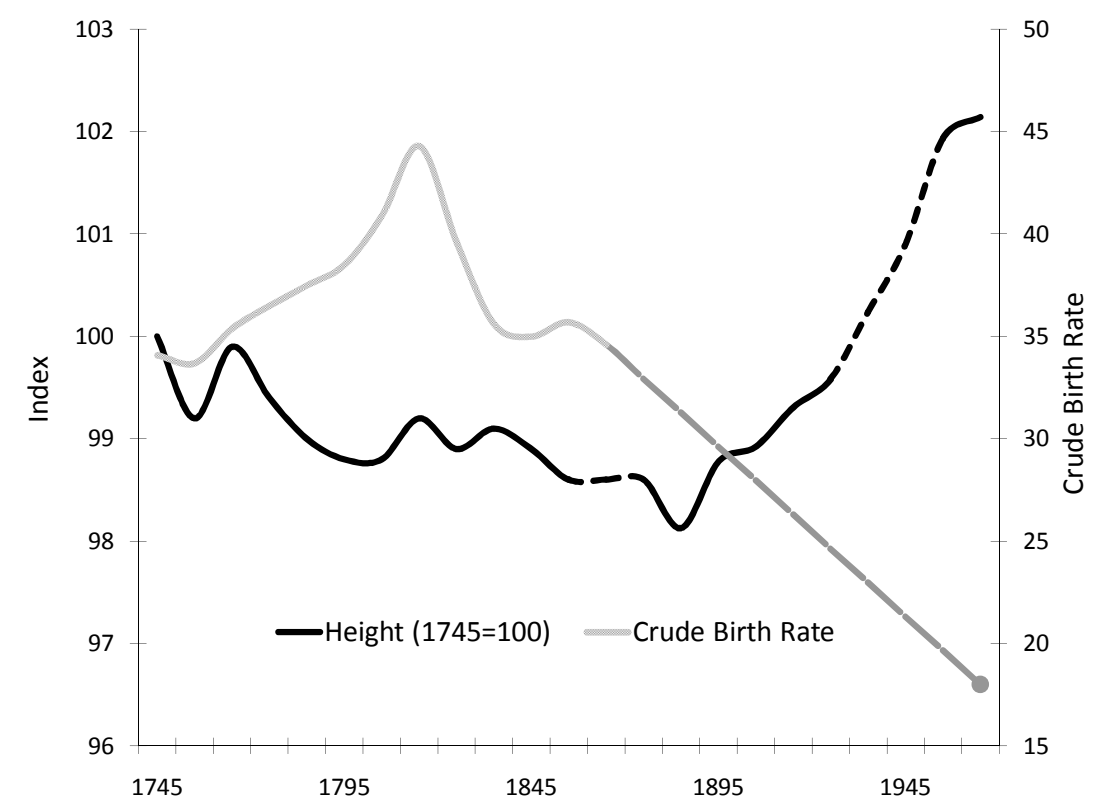

Sources: Wrigley and Schofield (1989) for crude birth rates 1790-1865. The crude birth rate for 1960 is from World Development Indicators (2005); rates in between calculated by simple linear interpolation (marked by dotted line). Komlos (1993, Table 6) for height data 17451855; army conscripts 20-23 year-olds. Height data for 1875-1925, 1955 and 1960 is taken from Boyer (2004, Table 11.5); army conscripts 20-24 year-olds. Notes: The two height series have been combined by assuming height was constant between 1855 and 1875 (marked by dotted line). The constancy between 1855 and 65 is supported by an actual constancy of height in the 18-19 year-old age bracket from 1845 to 1865 (Komlos, 1993, Table 6). The further constancy between 1865 and 1875 is a leap of faith. The period from 1925 to 1955 is a linear interpolation (marked by dotted line).

In the context of human populations micro evidence of the size-number trade-off is also available. In subsistence societies the inverse association between family size and size of the offspring has received support by Hagen et al. (2006) who examine the trade-off in the "Shuar" society, which resides in the tropical rainforests of Ecuador. Similarly, Walker et al. (2008) demonstrate a negative link between body size and family size across a sample of 16 subsistence-based societies. $^{4}$ At the household level an early study by Kuh and Wadsworth (1989), using data from a national survey conducted in the UK pertaining to children born in 1946, documented that conditional on a host of environmental factors, each additional sibling involved a reduction in mean height of about $6 \mathrm{~mm}$, in keeping with a size-number trade-off.

\footnotetext{
${ }^{4}$ See Cole (2000) and Silventoinen (2003) as well.
} 
From the perspective of the present study the evidence amassed by biologists and anthropologists is of substantive importance, since it makes plausible that the size-number trade-off is a fundamental one. The systematic link between reproduction and body size in economically primitive societies suggests that the trade-off must have been active for a very long time; certainly before the take-off to sustained growth occurred in Western Europe.

Within economics and economic history, the evidence is much more scarce. Weir (1993), demonstrates a strong negative association between height and fertility rates across regions in France during the period 1840-1911. Similarly, in the context of the English industrial revolution we observe a clear inverse association between body size and fertility: Whereas fertility undergoes an inverse U-shaped path, average body size (measured by height) displays a distinct U-shaped trajectory (cf. Figure 2). Whereas this latter regularity has long been viewed as a puzzle in the literature within anthropometric economic history (see Steckel, 2009, for a survey), the existence of a size-number trade-off allows us to capture it as a transitional phenomenon.

2.2. The Size-Number Trade-off in Europe. In a perhaps somewhat neglected contribution Schneider (1996) provided the first formal (cross-country) evidence in favor the quantity-quality trade-off emphasized in the present paper, by examining the link between fertility and average height in a panel of European countries. Below we revisit the study. In so doing we improve upon Schneider's study in terms of data coverage. Schneider examined nine European countries over the period 1750-1920 for a total of 101 observations, whereas we are able to examine 13 European countries from 1856-1980 (divided into five year epochs), for a total of 251 country-year observations. Hence, the following represents a meaningful out-of-sample check of Schneider's original findings. The data used below are described in the Data Appendix.

Formally, the empirical model for body size that Schneider proposed has the following form:

$$
\log \left(m_{i t}\right)=\beta n_{i t}+X_{i t}^{\prime} \gamma+c_{i}+\theta_{t}+u_{i t}
$$

where $i$ is a country index, and $t$ refers to time; $c_{i}$ is a country fixed effect, $\theta_{t}$ is a time varying intercept and $u_{i t}$ is noise. The left hand side variable $m_{i t}$ is adult body size, measured by average height, for individuals born around time $t$. $n_{i t}$ is fertility, which we proxy by the crude birth rate. $X_{i t}$ includes additional time varying controls. Following Schneider we introduce mortality, measured by the crude death rate (CDR), income, measured by GDP per capita, and a dummy for World War I. It is important to stress that the right hand side variables all speak to the 
conditions around the birth year of the cohort. Accordingly, reverse causality (from body size to per capita income, say) can be ruled out. The object of interest is $\beta$, and the prediction is that $\hat{\beta}<0 .^{5}$

Figure 3 provides a simple cross-plot between fertility and adult body size, pooling all countryyear observations. Consistent with the proposed quantity-quality trade-off a clear negative correlation is apparent. Yet this simple correlation may be spurious, driven instead by various omitted factors. Hence, for a more adequate assessment of the correlation formal regression analysis is warranted. Table 1 reports the results from estimating equation (1). In the first column the correlation from Figure 3 is reexamined when country fixed effects are taken into account, and column 2 further adds time fixed effects. The latter has a marked impact on the point estimate for $n$, which drops considerably in absolute value. However, introducing the additional controls proposed by Schneider (1996) has little impact on the economic and statistical significance of fertility.

Column 6 replicates the "full specification" adopted by Schneider, which involves a time trend rather than time fixed effects. The results are comparable to those recovered by Schneider: fertility as well as income per capita turn out to be significant, along with the time trend and the world war I dummy: cohorts born during the first world war grew up to be slightly shorter than what would be expected based on the controls. In light of our bigger sample column 7 explores adding indicators for the second world war, and the great depression. Interestingly, the great depression also seems to have left a dent in European body size, comparable in magnitude to that of World War I. However, whereas Schneider finds mortality to be - marginally - significant, the crude death rate is insignificant in our expanded sample. Moreover, if the time trend is replaced by time dummies, income per capita is also rendered insignificant (cf. Column 4). In contrast, the crude birth rate continues to be significant at the five percent level of confidence. As can be seen from the $R^{2}$ the model appears to do a good job at spanning the variation in the data.

\footnotetext{
${ }^{5}$ While reverse causality is not an issue it is worth noting that the interpretation of the coefficients on log income per capita around the time of birth involves some ambiguity. One interpretation is nutritional; in periods of high income and low mortality (low disease) the net-nutritional intake should be high leading to bigger adults down the line. This is the interpretation Schneider (1996) seems to have in mind. Yet another interpretation is the following. In the theory below we demonstrate that, conditional on nutrition, the size of the mother matters to adult stature. Hence, if income per capita during childhood is correlated with the size of the mother the coefficient on the former potentially convolutes an intergenerational influence from parental size. In particular, this interpretation would imply that the coefficient on income represents an upper bound on the impact from nutrition during childhood on adult stature.
} 
Figure 3: Body size vs. Fertility: 13 European countries 1856-1980

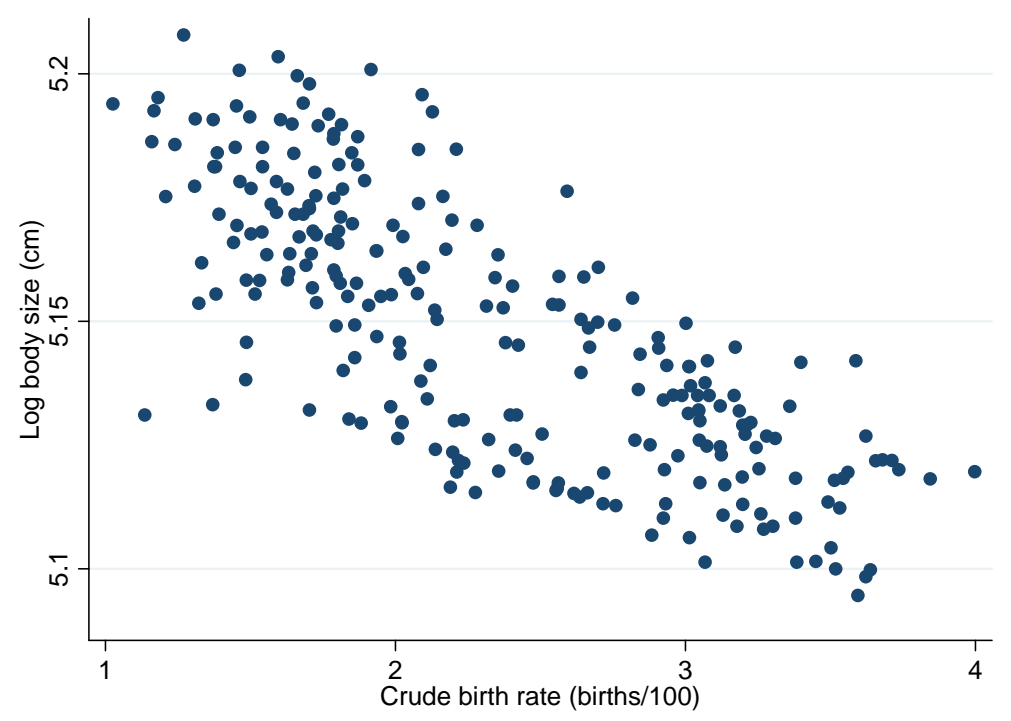

The figure shows the pure correlation between adult body size $(\mathrm{cm})$ and fertility (crude birth rate in birth year) pooling cross-section and time series information. Data: See Data Appendix.

Table 1: Adult Body Size and Birth Rates: 13 European Countries 1856-1980

\begin{tabular}{|c|c|c|c|c|c|c|c|}
\hline \multirow[b]{2}{*}{ Variables } & (1) & (2) & (3) & (4) & (5) & (6) & (7) \\
\hline & \multicolumn{7}{|c|}{ Log Body Size $(\mathrm{cm})$} \\
\hline Crude Birth Rate & $\begin{array}{c}-0.028^{* * *} \\
(0.002)\end{array}$ & $\begin{array}{l}-0.005^{*} \\
(0.003)\end{array}$ & $\begin{array}{c}-0.005^{* *} \\
(0.002)\end{array}$ & $\begin{array}{l}-0.005^{*} \\
(0.003)\end{array}$ & $\begin{array}{c}-0.005^{* *} \\
(0.002)\end{array}$ & $\begin{array}{l}-0.003^{*} \\
(0.002)\end{array}$ & $\begin{array}{c}-0.005^{* *} \\
(0.002)\end{array}$ \\
\hline Crude Death Rate & & & $\begin{array}{c}0.000 \\
(0.003)\end{array}$ & & $\begin{array}{c}0.000 \\
(0.003)\end{array}$ & $\begin{array}{l}-0.001 \\
(0.003)\end{array}$ & $\begin{array}{l}-0.002 \\
(0.003)\end{array}$ \\
\hline Log GDP per Capita & & & & $\begin{array}{c}0.005 \\
(0.004)\end{array}$ & $\begin{array}{c}0.005 \\
(0.004)\end{array}$ & $\begin{array}{c}0.010^{* * *} \\
(0.003)\end{array}$ & $\begin{array}{l}0.010^{* *} \\
(0.004)\end{array}$ \\
\hline Time Trend & & & & & & $\begin{array}{c}0.000^{* * * *} \\
(0.000)\end{array}$ & $\begin{array}{c}0.000^{* * *} \\
(0.000)\end{array}$ \\
\hline World War I & & & & & & $\begin{array}{c}-0.004^{* *} \\
(0.001)\end{array}$ & $\begin{array}{c}-0.004^{* *} \\
(0.001)\end{array}$ \\
\hline World War II & & & & & & & $\begin{array}{c}0.001 \\
(0.002)\end{array}$ \\
\hline Great Depression & & & & & & & $-0.005^{* * *}$ \\
\hline & & & & & & & $(0.002)$ \\
\hline Time FE & No & Yes & Yes & Yes & Yes & No & No \\
\hline Country FE & Yes & Yes & Yes & Yes & Yes & Yes & Yes \\
\hline Observations & 251 & 251 & 251 & 251 & 251 & 251 & 251 \\
\hline R-squared & 0.785 & 0.958 & 0.958 & 0.959 & 0.959 & 0.943 & 0.947 \\
\hline Number of id & 13 & 13 & 13 & 13 & 13 & 13 & 13 \\
\hline
\end{tabular}

Standard errors are clustered at the country level; ${ }^{* * *} p<0.01,{ }^{* *} p<0.05,{ }^{*} p<0.1$. The crude birth rate, death rate and average income refers to conditions in the birth year of the cohort. Hence, measurement the right hand side variables (CBR, CDR, GDP per capita) are lagged 20 years compared with the year of observation for body size. 
Reverse causality is, as noted above, unlikely to be important in the present setting. While omitted variable bias cannot be ruled out, it is clear that the model accounts well for the variation in the data, thus leaving only modest room for further improvements in the overall fit. In any case, it is not clear that potentially omitted variables necessarily would bias the results in a direction favorable to the hypothesis under examination.

The out-of-sample check largely corroborate Schneider's original findings, yet suggests that mortality may have played a more modest role in accounting for rising body size than what one might have expected based on Schneider (1996). This suggests that the modeling simplification invoked below (absence of premature death) is fairly reasonable, when the objective is to study the long-run evolution of average body size. In sum, the results reported in Table 1 provide corroborating evidence in favor of the key quantity-quality trade-off highlighted by the proposed theory: greater fertility rates during childhood are associated with lower adult body size.

\section{The Model}

Consider an economy in the process of development. The economy is closed, and time is discrete. It comprises two sectors, each producing a unique good: agricultural goods and nonagricultural goods, respectively. The only accumulable input of production is labor; labor is fully mobile between the two sectors. People live for two periods: childhood (after weaning) and adulthood. In the model we ignore matching problems; adults are thus assumed to reproduce asexually. The remaining details of the model are given below.

3.1. The Evolution of Body Size Across Generations. Recently West et al. (2001) have established and tested a theory of ontogenetic growth, built up from first principles, which we draw on in order to derive the law of motion of body tissue across generations. Following Dalgaard and Strulik (2015) we integrate the work of West et al. into the present discrete time OLG structure in the following way.

The starting point is an energy conservation equation:

$$
E_{t}^{c}=b_{c} N_{t}+e_{c}\left(N_{t+1}^{\prime}-N_{t}\right)
$$

in which $E_{t}^{c}$ is energy consumption during childhood after weaning (prior consumption is covered by adult metabolic needs, as explained below), $N_{t}$ denotes the number of human cells after weaning, $N_{t+1}^{\prime}$ is the number of cells of the child as a grown up, $b_{c}$ is the metabolic energy a 
cell requires during childhood for maintenance and replacement, and $e_{c}$ the energy required to create a new cell. Hence the left hand side is energy "input", and the right hand side captures energy use. Solving (2) for $N_{t+1}^{\prime}$ we obtain the number of cells of an adult as a function of the number of cells of a child after weaning and energy intake during childhood:

$$
N_{t+1}^{\prime}=\frac{E_{t}^{c}}{e_{c}}+\left(1-\frac{b_{c}}{e_{c}}\right) N_{t}
$$

To proceed we insert the fact that body mass consists of the mass of a single cell $\bar{m}$ times the number of cells. This implies for the size of an adult that $m_{t+1}=\bar{m} N_{t+1}^{\prime}$. Moreover, using the fact that after weaning the size of a child equals $\mu$ times the size of the mother (Charnov, 1991, 1993) we have $\bar{m} N_{t}=\mu m_{t} .{ }^{6}$ Substituting $N_{t}$ and $N_{t+1}^{\prime}$ in (6) and and solving for $m_{t+1}$, gives (4):

$$
m_{t+1}=\frac{\bar{m}}{e_{c}} E_{t}^{c}+\left(1-\frac{b_{c}}{e_{c}}\right) \mu m_{t} .
$$

This intergenerational law of motion for body size has a simple interpretation: The size of the adult, $m_{t+1}$ is determined by energy consumption during childhood, $E_{t}^{c}$, plus initial size, $\mu m_{t}$, adjusted for energy needs during childhood, $-\left(b_{c} / e_{c}\right) \mu m_{t}$. Finally, denote by $c_{t}$ the consumption of a child, to be determined below from optimization. Then total energy intake during childhood is $c_{t} \cdot \epsilon=E_{t}^{c}$, where $\epsilon$ converts units of goods into calories. Inserting this into (4) leaves us with a law of motion for body size across generations:

$$
m_{t+1}=a \cdot \epsilon \cdot c_{t}+(1-d) \cdot \mu \cdot m_{t}
$$

where $a \equiv \bar{m} / e_{c}$ and $d \equiv b_{c} / e_{c}$. This is the intergenerational law of motion for body size, which we will invoke below.

3.2. Metabolic Needs of Adults. Once the individual reaches adulthood we assume her body size remains constant for the remainder of her life; we are thus focusing on the irreversible component of body size. At the time when individuals make economic choices, the body size is therefore predetermined. ${ }^{7}$

\footnotetext{
${ }^{6}$ A physiological justification for this assumption is that child development until weaning depends on energy consumption in utero and during the breastfeeding phase. Since larger mothers consume absolutely more energy the offspring should be larger at this point as it receives a fraction thereof. With this interpretation the linearity should be seen as a simplification. It has no substantive implications for our main results if the linearity is relaxed except for reduced tractability.

${ }^{7}$ We could add food demand of adults beyond metabolic needs without implications for our main results. Since height is fixed for adults, excess food demand would lead to overweight and obesity. Investigating the evolution
} 
During adulthood individuals are subject to subsistence requirements which depend on body size and on fertility. In particular, we use the fact that rearing up a child from conception to weaning requires a fraction $\rho$ of the mother's metabolic energy (Prentice and Whitehead, 1987; Sadurskis et al., 1988). With $E_{t}$ denoting total energy consumed by adults and $B_{t}$ denoting the basal metabolic rate of the mother we thus have $E_{t}=(1+\rho n) \cdot B_{t}$.

Finally, the basal metabolic rate of the mother is determined by Kleiber's law, $B_{t}=B_{0} m_{t}^{b}$ (Kleiber, 1932). Kleiber's law states that energy consumption increases with body mass at factor $b \approx 3 / 4$; this association has by now been verified for (virtually) all animals and living organisms. In addition it can be derived theoretically as a manifestation of how energy is diffused and absorbed in a biological organism under optimal conditions, as would emerge through natural selection (West et al, 1997). Hence, this mapping can be given rigorous micro foundations. Inserting it into the above energy constraint for adults provides: ${ }^{8}$

$$
E_{t}=(1+\rho n) \cdot B_{t}=(1+\rho n) \cdot B_{0} m_{t}^{b}, \quad B_{0}>0, \quad b=3 / 4
$$

3.3. Individual's Optimization. Facing the energy constraint of their own metabolic needs, adults derive utility from the number of children $n_{t}$, nutritional expenditure for each child $c_{t}$, and consumption of manufactured goods $q_{t}$. Specifically, we assume the following utility function:

$$
u_{t}=q_{t}+\gamma \log \left(n_{t}\right)+\frac{\left(c_{t} n_{t}\right)^{1-\sigma}}{1-\sigma}, \quad \sigma>1
$$

where the compound $c_{t} n_{t}$ is total child expenditure or "child quality" in the sense of Becker (1960).

While perhaps unfamiliar looking the utility function is not of arbitrary structure. In order to generate meaningful results we rely on a "hierarchy of needs" principle. The principle adapted is that nourishment of offsprings (and, implicitly, of the adult via subsistence requirements) is a first priority activity, family planning comes next, and expenditure on manufactured goods, i.e. goods for convenience and entertainment, comes last. To capture this, preferences are described by a utility function in which the elasticity of marginal utility is highest for child nutrition,

of obesity in modern societies is an interesting field of research in its on right; but overweight is a problem of second order for the period under consideration, and it is thus neglected for simplicity.

${ }^{8}$ In principle, we could distinguish between energy expended at rest and in activity. In a representative agent study, however, this just complicates the algebra without new insights. The distinction between metabolic needs at rest and in activity becomes "only" interesting in a heterogenous agent framework, as shown in Dalgaard in Strulik (2011) in the context of efficiency wages. 
second highest for fertility and lowest for consumption of manufactured goods. This means that in times of crises parents try to smooth nutrition of their offsprings relatively stronger than their family size, and family size stronger than consumption of manufactured goods.

The basic idea of a hierarchy of needs goes back to the work of the psychologist Abraham Maslow (1943). In particular, Maslow argued that physiological needs, and safety needs, take precedent over the establishment of a family. While the notion that such universal needs exist - and can be ranked - has been controversial in psychology, recent empirical work has provided some corroborating evidence in favor of Maslow's needs hierarchy (Tay and Diener, 2011). Moreover, empirical studies of household behavior in times of crises show that households try especially hard to smooth calorie consumption, while allowing other consumption items to adjust (e.g. Frankenberg et al, 2003; Stillman and Thomas, 2008). In particular, periods of crisis has been shown to be associated with deferred marriage, lower marital fertility, or both (Lee, 1990; Caldwell, 2004). The above utility function is therefore designed to replicate this type of behavior. $^{9}$

Turning next to the budget constraint, let $w_{t}$ denote income (measured in units of the manufactured good) and $p_{t}$ the relative price of food. Then the budget constraint of a parent is given by the following equation:

$$
w_{t}=q_{t}+p_{t} c_{t} n_{t}+p_{t}\left(1+\rho n_{t}\right) \cdot \frac{B_{0} m_{t}^{b}}{\epsilon}
$$

where subsistence needs have been converted from units of energy (kcal. per period) into units of goods by applying the energy exchange rate introduced above.

The individuals' problem consist of choosing family size $n_{t}$, expenditure per child $c_{t}$, and non-food consumption $q_{t}$ so as to maximize (7) subject to (8). From the first order conditions we obtain:

$$
\begin{aligned}
n_{t} & =\frac{\gamma \epsilon}{p_{t} \rho B_{0} m_{t}^{b}} \\
c_{t} & =\frac{\rho B_{0} m_{t}^{b}}{\gamma \epsilon} \cdot p_{t}^{(\sigma-1) / \sigma} .
\end{aligned}
$$

\footnotetext{
${ }^{9}$ Other studies that invoke a hierarchy of needs principle, where fertility takes precedent over material consumption, includes Weisdorf, 2008, Strulik and Weisdorf (2008) and Vollrath (2009). Strulik and Weisdorf (2012) discuss child mortality issues in this context. Foellmi and Zweimueller (2006, 2008) investigate hierarchical preferences and structural change in a more general context, see also Kongsamut et al. (2001).
} 
Observe the influence from the relative price of food: both fertility $n_{t}$ and (combining the two first order conditions) total quality investments $c_{t} n_{t}=p_{t}^{-1 / \sigma}$ decrease when food (and thus children) become relatively more expensive. Nutrition per child, however, improves as food prices go up. Hence, industrialization, associated with rising $p_{t}$, will imply higher expenditure on manufactured goods, smaller families, less food expenditure, and better nutrition per child.

3.4. Production. Food is produced in an agricultural sector (indexed by $A$ ) and non-food is produced in an industrial sector (indexed by $Q$ ). The production functions are

$$
\begin{gathered}
Y_{t}^{A}=A_{t}\left(L_{t}^{A}\right)^{\alpha} \\
Y_{t}^{Q}=Q_{t} L_{t}^{Q} .
\end{gathered}
$$

Here, $L_{t}^{A}$ and $L_{t}^{Q}$ denote sectoral labor inputs and $A_{t}$ and $Q_{t}$ denote sector specific productivity. Agriculture may be subject to decreasing returns originating from limited land (normalized to one), i.e. $\alpha \leq 1 .^{10}$

Let $L_{t}$ denote the number of adults at time $t$. Ignoring, for simplicity, child mortality the adult population (workforce) evolves according to

$$
L_{t+1}=n_{t} L_{t}
$$

This completes the model.

3.5. General Equilibrium. In order to derive the static general equilibrium consider the nonarbitrage condition associated with the decision to work in the $A$ and $Q$ sector, respectively. Assuming labor is compensated by the average product in agriculture the condition is that

$$
w_{t}=p_{t} A_{t}\left(L_{t}^{A}\right)^{\alpha-1}=Q_{t}
$$

Let $v_{t}$ denote total food demand per family in period $t, v_{t}=p_{t}\left(c_{t} n_{t}+\left(1+\rho n_{t}\right) B_{0} m_{t}^{b} / \epsilon\right.$. After inserting (9) and (10) we get food demand as a function of food prices and body size:

$$
v_{t}=\left[\gamma+p_{t}^{\frac{\sigma-1}{\sigma}}+p_{t} B_{0} m_{t}^{b} / \epsilon\right] / p_{t}
$$

\footnotetext{
${ }^{10}$ In Dalgaard and Strulik (2015) we allow $m$ to enter the production function, which has important implications in a pre take-off setting. In the present context, however, the productive influence from body size will quickly "vanish" once technology takes off. Hence, in the interest of simplicity we leave it out.
} 
Food market clearing requires that demand equals supply, $Y_{t}^{A}=v_{t} L_{t}$, which after inserting (11) and (15) can be stated as

$$
A_{t}\left(L_{t}^{A}\right)^{\alpha}=\left[\gamma+p_{t}^{\frac{\sigma-1}{\sigma}}+p_{t} B_{0} m_{t}^{b} / \epsilon\right] L_{t} / p_{t}
$$

Finally, substituting $L_{t}^{A}$ from (14) provides an implicit function for prices in equilibrium.

$$
f\left(p_{t}\right)=p_{t}^{1 /(1-\alpha)}\left(\gamma+p_{t}^{(\sigma-1) / \sigma}+\frac{p_{t} B_{0}}{\epsilon} m_{t}^{b}\right) \cdot L_{t}-\left(\frac{A_{t}}{Q_{t}^{\alpha}}\right)^{1 /(1-\alpha)}=0 .
$$

Note that population size $L_{t}$ and body size $m_{t}$ as well as technology in agriculture and manufacturing, $A_{t}$ and $Q_{t}$, are state variables, which are predetermined in period $t$.

Proposition 1. (General Equilibrium). A general equilibrium exist, and it is unique.

Proof. It is easy to verify that $f\left(p_{t}\right)$ is monotonically increasing in $p_{t}$ with $\lim _{p \rightarrow 0} f(p)<0$ and $\lim _{p \rightarrow \infty} f(p)=\infty$; (17) therefore pins down the unique equilibrium price associated with clearing in the markets for $A$-goods, labor and thus also $Q$-goods.

Corollary 1. Equilibrium food prices are a positive function of population density $(L)$, of body size $(m)$, of productivity in manufacturing $(Q)$, and the weight for children in parental utility $(\gamma)$. They are a negative function of the level of agricultural productivity (A) and of the energy exchange rate $(\epsilon)$.

Proof. Follows from (17) and the implicit function theorem.

These results are quite intuitive. For instance, a larger number of people and a larger number of body cells per person drive up food demand and thus, given supply, equilibrium prices for food. In short, for given land, diet, and level of technology, our model predicts food prices to be higher in more densely populated areas and for societies consisting of, on average, physically larger individuals. The remaining comparative statics are straightforward to interpret via their impact on supply or demand. However, they only relate to the short run, where the size of population and average body size of the citizen's are given. In the long-run changes in these parameters may affect the economy through fertility and body size. To clarify their overall impact we need to understand the dynamic properties of the model.

3.6. Steady State. At a stationary state, knowledge in agriculture and manufacturing does not change, $A_{t}=A_{t+1}=A$ and $Q_{t}=Q_{t+1}=Q$. Inserting equations (9) and (10) into (4) and 
(13) we obtain the law of motion for body size and population size, respectively:

$$
\begin{aligned}
& m_{t+1}=a(\rho / \gamma) B_{0} \cdot m_{t}^{b} \cdot p_{t}^{(\sigma-1) / \sigma}+(1-d) \mu m_{t} \\
& L_{t+1}=\frac{\gamma \epsilon}{\rho p_{t} B_{0} m_{t}^{b}} \cdot L_{t} .
\end{aligned}
$$

Proposition 2. (Steady State.) The exists a unique steady state $\left(m^{*}, L^{*}\right)$ at

$$
\begin{gathered}
m^{*}=\left(\frac{a \epsilon^{\frac{\sigma-1}{\sigma}}\left(\rho B_{0} / \gamma\right)^{1 / \sigma}}{1-(1-d) \mu}\right)^{\frac{1}{1-b / \sigma}} \\
L^{*}=\frac{\left(p^{*}\right)^{[1+\alpha(\sigma-1)] /[(1-\alpha) \cdot \sigma]}}{1+(1+\rho) \cdot \gamma / \rho \cdot\left(p^{*}\right)^{\frac{1-\sigma}{\sigma}}} \cdot\left(\frac{A}{Q^{\alpha}}\right)^{1 /(1-\alpha)},
\end{gathered}
$$

where the relative price of agricultural goods is given by:

$$
p^{*}=\left[\left(\gamma / \rho B_{0}\right) \cdot a^{-b} \cdot(1-(1-d) \mu)^{b}\right]^{\frac{1}{1-b / \sigma}} \cdot \epsilon^{\frac{\sigma(1-b)}{\sigma-b}}
$$

Proof. Since $L_{t}$ is constant at the steady-state, $n_{t}=1$, implying the equilibrium price of food

$p_{t}=p^{*}=\gamma \epsilon /\left(\rho B_{o} m^{* b}\right)$. Taller people in equilibrium cause, ceteris paribus, a higher relative price for food, since more body cells have to be fed. Inserting this information into (18) we get equilibrium body size. Finally, inserting equilibrium prices and equilibrium body size in (19) and solving this equation at the steady-state one gets, after some additional manipulations, the expression for equilibrium population size.

3.7. Comparative Statics. Since $1-b / \sigma>0$ the following comparative statics can be straightforwardly read off equation (20):

\section{Proposition 3. (Determinants of Long-Run Body Size.)}

(I) Steady state body size increases if: (a) the weight of children in utility $\gamma$ declines, (b) the energy costs of creating a cell or maintaining a cell declines (smaller d or larger a), or, (c) the energy exchange rate $(\epsilon)$ rises.

(II) Steady state body size is independent of: (a) the level of productivity $(A, Q)$ and (b) the nature of the production technology $(\alpha)$

Inspection of equations (22) and (21) reveals the following result:

Proposition 4. (Determinants of Long-Run Population Size.) Steady state population size increases if: (a) the weight of children in utility $\gamma$ increases, (b) the energy costs of creating 
a cell or maintaining a cell increases (smaller $d$ or larger a), (c) the energy exchange rate ( $\epsilon$ ) increases, (d) the level of productivity in agriculture (A) rises, (e) the level of productivity in non-food production (Q) falls.

Of particular interest is the invariance of average body size to technological parameters. The intuition is as follows. Consider an increase in $A$, i.e., a technological advance in agriculture. In the short run this increase works so as to lower the relative price of provisions, which in turn stimulates fertility. In the next generation, therefore, the population has risen, which works to increase the demand for food producing a rising price of agricultural goods that suppresses fertility. The economy therefore gradually moves towards a new steady state featuring the same relative level of prices (cf. proposition 2) and the same average body size but a greater population density due to the temporary increase in fertility during transition. A similar argument pertains to changes in $Q$ (or $\alpha$ ), which also only has a temporary impact on relative food prices and therefore on fertility. Hence, as long as productivity growth is very slow (so that constant $A$ and $Q$ are a relevant approximation), body size remains constant. ${ }^{11}$

Another interesting comparative static is that concerning the energy exchange rate: When more calories can be extracted from one unit of food expenditure, i.e. when $\epsilon$ rises, parents provide more nutrition for their children in the long-run, for which reason steady state body size rises. The interpretation is as follows. Starting at steady state, imagine $\epsilon$ increases permanently; say, as a consequence of the discovery of a new crop. At the time of impact (i.e., for $L$ and $m$ given) the increase in $\epsilon$ lowers the price of food (cf. Corollary 1). This induces parents to have more children, but to provide less nutrition per child. In the long-run, however, the temporary increase in fertility translates into a permanent increase in population, which works to raise the steady-state relative price of agricultural goods (see (22)). Hence, at the new steady state, due to the hierarchy of needs principle, parents are investing slightly more in nutrition per child, leading to greater stature.

The remaining parameters' influence on long-run body size and density are quite intuitive. Consider a reduction in energy costs at the cellular level; a smaller $d$ or $a$. On impact such reductions will serve to increase body size, for nutritional investments given, as a given amount of energy input leads to the creation of more cells. In the next generation people will therefore be

\footnotetext{
${ }^{11}$ In Dalgaard and Strulik (2015) we provide evidence that proxies for agricultural productivity do not have any impact on average body size in contemporary hunter gather societies (or societies dominated by primitive agriculture), yet serve to increases population density, in keeping with Proposition 3 and 4.
} 
bigger. However, to bigger people the metabolic costs of child rearing are greater (see equation (9) and (10)), which induces them to have fewer children but feed them better. In the long run, average body size therefore increases since the parameter change (which could be due to natural selection as discussed below) changes the nature of the quality-quantity trade off in favor of quality. The same is true when preferences change (i.e., changes in $\gamma$ ); lower preferences for child quantity will eventually produce less densely settled communities where people on average are physiologically bigger.

\section{Balanced Growth: The Take-off and Beyond}

In this section we introduce endogenous growth of knowledge in agriculture and manufacturing. Since market financed R\&D is a relatively new phenomenon (Mokyr, 2005), we follow Strulik and Weisdorf (2008) and assume that learning-by-doing drives productivity. That is, $\Delta A_{t} \equiv A_{t+1}-A_{t}=\nu\left(Y_{t}^{A}\right)^{\xi}$ and $\Delta Q_{t} \equiv Q_{t+1}-Q_{t}=\delta\left(Y_{t}^{Q}\right)^{\phi}$. Reasonably, we assume decreasing returns of learning-by-doing, that is $0<\xi<1$ and $0<\phi<1$.

Inserting the production technologies (11) and (12) and solving for sectoral growth rates of knowledge we obtain:

$$
g_{t+1}^{A} \equiv \frac{A_{t+1}-A_{t}}{A_{t}}=\nu\left(A_{t}\right)^{\xi-1}\left(L_{t}^{A}\right)^{\alpha \xi}-1, \quad g_{t+1}^{Q} \equiv \frac{Q_{t+1}-Q_{t}}{Q_{t}}=\delta\left(Q_{t}\right)^{\phi-1}\left(L_{t}^{Q}\right)^{\phi}-1 .
$$

The specific adjustment dynamics are determined via calibration. But it is useful to consider the basic elements that drive the dynamics upfront. For this purpose we inspect the relative price of food derived from (14) and the labor share in agriculture derived from (16) and (15).

$$
\begin{aligned}
p_{t} & =\frac{Q_{t} L_{t}^{1-\alpha}}{A_{t}} \\
\frac{L_{t}^{A}}{L_{t}} & =\left(p_{t}^{(\sigma-1) / \sigma}+p_{t} B_{0} m_{t}^{b} / \epsilon+\gamma\right) \cdot \frac{1}{Q_{t}} .
\end{aligned}
$$

Consider an economically backward society. The level of productivity in both sectors is very low, for which reason wages are low. $Q$ is particularly low since, as a reasonable initial condition, most of the labor force is employed in the A sector. As a consequence, manufactured goods are relatively expensive, and its demand is therefore modest.

Most of the population is working in agriculture; $L_{t}^{A} / L_{t}$ is high (see (25)). As a result of this allocation of labor the speed of knowledge creation is faster in agriculture which creates a tendency of food prices to fall (see (24)). However, given falling food prices people reproduce 
at higher rates and productivity growth is (almost completely) compensated by population growth such that income remains (almost) constant. Yet, continual population growth and food production gradually raise the speed of learning in agriculture such that $p_{t}$ falls. With rising productivity in agriculture, the sector releases labor for production of manufactured goods. The process is slow at first, but gradually gains momentum. The shifting output structure influences the productivity growth gap. Eventually a point is reached where the relative price of food begins to increase and fertility falls. This process also affects the quantity-quality trade-off: with rising $p_{t}$ and falling fertility nutritional expenditure per child begins to rise. A quantityquality trade-off sets in during industrialization, leading to larger body size.

The take-off of economic growth and ontogenetic growth, however, are phenomena of transitional dynamics and another interesting question is whether a time path exists along which body size stays constant. From (18) we see immediately that this requires the price of food to be constant. Otherwise, parents would have an incentive to further increase (or reduce) food provision per child. From (19) we see that a constant price implies constant population growth because the preferred number of offspring stays constant. Let a balanced growth path be defined as a time path along which both sectors grow at a common rate (possibly zero) such that neither the production of food nor the production of manufactured goods vanishes asymptotically. From (25) it then follows that only a stationary population supports balanced growth. Otherwise there would be Malthusian dynamics operating towards increasing food prices if the population continues to grow or decreasing food prices if the population shrinks. With a stationary population, however, there are no scale effects of learning-by-doing, and the (exponential) power of knowledge growth peters out. The following proposition (proven in the Appendix) shows that the balanced growth path does not only exist and is unique but that it is also stable under a mild condition.

Proposition 5. (Existence of a balanced growth path) If $\phi /(1-\phi)+1-\alpha<\alpha \xi /(1-\xi)$, the economy converges towards a balanced growth path of constant prices, constant body size, zero population growth, and zero (exponential) economic growth.

The condition rules out explosive growth, that is a path where agricultural productivity and population size are jointly exploding. Intuitively, along such a path people learn new techniques in agriculture so quickly (compared to learning in manufacturing) that the prices for agricultural 
goods decrease perpetually and fuel further population growth. This counter-factual scenario can always be avoided by choosing a sufficiently small learning parameter for agricultural knowledge.

4.1. Calibration. In order to evaluate the mechanics of the model along the adjustment path towards the long-run steady-state, we set out with a calibration for England. We begin by setting $B_{0}=70$ and $b=0.75$ according to Kleiber's (1932) law. Following Prentice and Whitehead (1987) we put $\rho=0.15$ implying that a woman who is pregnant with a child must consume 1.2 times the energy of a non-pregnant woman. According to the WHO (2006) a grown up female weighs on average $m=59 \mathrm{~kg}$ and a female child weighs on average $9 \mathrm{~kg}$ after weaning, assuming weaning after 12 months. This implies that, on average, $\mu=0.15$. With respect to body size we have to confront the problem that there are no detailed long-run historical time series for females and that the available series for males provide body size in terms of height rather than weight. We deal with the problem of converting body size into height (stature), denoted by $s_{t}$, by using a body mass index (BMI) of 21.5 and the formula $s_{t}=\sqrt{m_{t} /(B M I)}$. Since we have one degree of freedom with the physiological parameters we set $d=0.5$ and adjust $a$ such that equilibrium height is 1.82 meter, $5 \mathrm{~cm}$ above the current average height of 20 year old males in England.

The specific size of the physiological parameters is not decisive for the shape of transitional dynamics. These are crucially determined by technologies and preferences. We begin with setting $1-\alpha$ to 0.2 according to Clarke's (2007) average estimate of the share of land in agriculture. We set parameters such that the predicted time series for population growth, body size, and productivity growth in manufacturing approximate best the historical times series for England and Wales before, during, and after the industrial revolution and the demographic transition. This leads to the estimates $\xi=0.4, \phi=0.95, \nu=24, \delta=2.4, \sigma=1.25$ and $\epsilon=1.2$. The estimates of $\xi$ and $\phi$ imply a relatively flat learning curve in agriculture and a relatively steep learning curve in manufacturing. They produce a long phase of low productivity growth in agriculture, which mainly translates into population growth; economic development therefore proceeds at a slow rate. During this Malthusian phase most workers are occupied with agriculture such that learning in manufacturing is slow as well. The gradual movement of labor into manufacturing, however, eventually leads to relatively high productivity growth in this sector, which is then further fueled by fast learning-by-doing and not slowed down (as in agriculture) by decreasing return with respect to labor input. Thus, once initiated, the industrial revolution is relatively 
quick compared to the slow evolution in the centuries before. The estimate of $\sigma$ implies a price elasticity of food demand (beyond metabolic needs of the parent) of 0.2 , a value close to Clark's (2007b) estimate of the price elasticity of food near subsistence consumption.

Figure 4: Long-Run Economic and Physiological Development
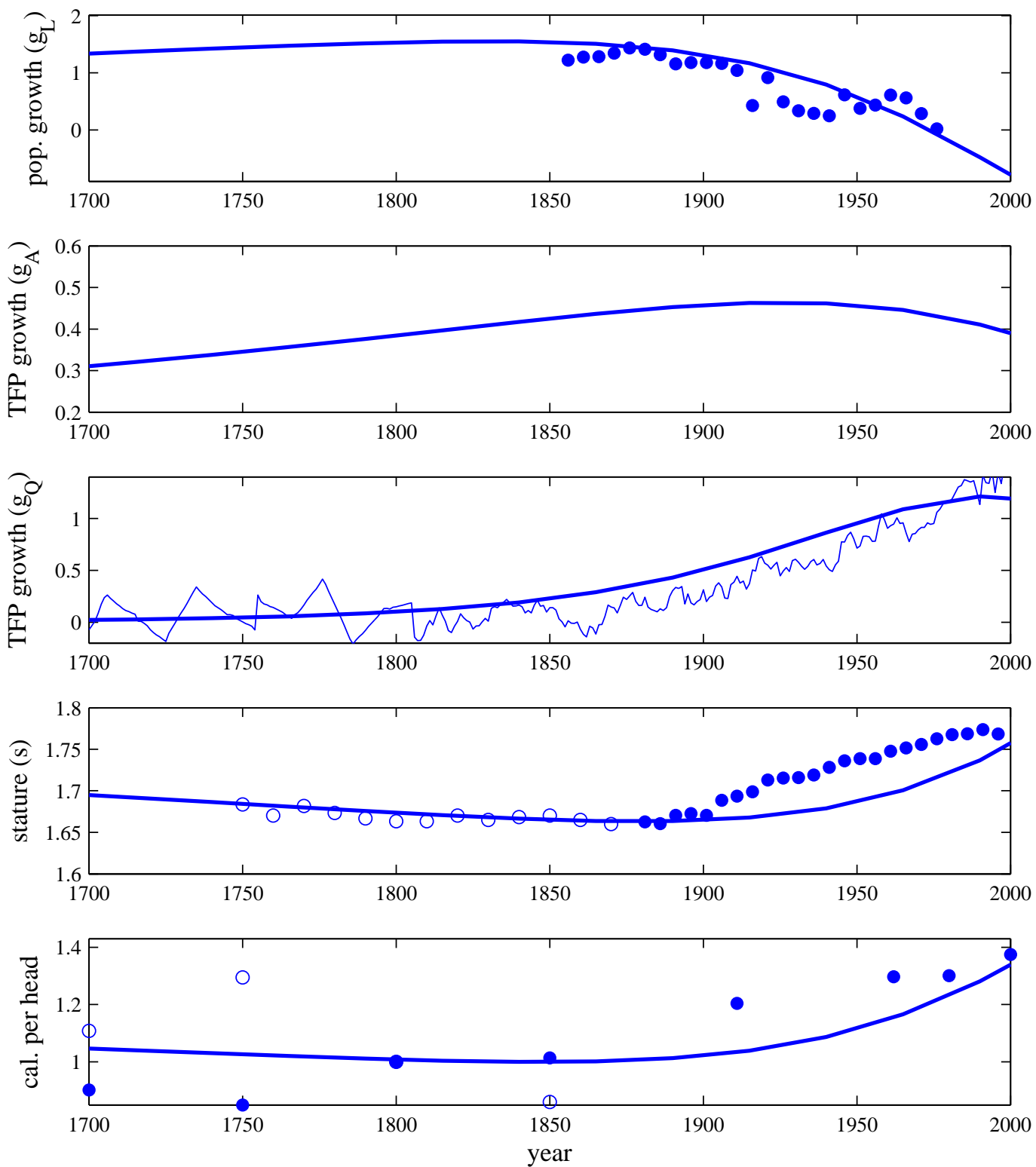

Bold lines: model prediction for England (see text for calibration details). Data: population growth: net rate of reproduction England and Wales from Reher (2004). Stature: solid dots (s): Hatton and Bray (2010); white dots Komlos (1993). TFP growth (thin line): Madsen et al. (2010). Calorie consumption per head: solid dots: Floud et al. (2011) and FAO (2012); white dots (Allen, 2005). 
4.2. Long-Run Adjustment Dynamics and Implications. Figure 4 shows the long-run dynamics predicted by our baseline calibration. In order to compare results with the historical time series we have assumed that a generation takes 25 years and converted generational growth rates into annual ones. We have started the economy at year $0 \mathrm{AD}$ close to the subsistence steadystate and adjusted initial values of the state variables such that the fertility transition and the rise of body size are set in motion in the mid 19th and early 20th century, respectively. The figure focusses on the most interesting time window around the Industrial Revolution and the take-off of body size from year 1700 to 2000. As can be seen, net fertility (population growth) peaks around 1850, agricultural productivity peaks around 1920 and industrial productivity peaks in the late 20 th century.

The predicted trajectories approximate the historical time series for net fertility (data from Reher, 2004), TFP growth (data from Madsen et al., 2010) and stature (data from Komlos, 1993, and Hatton and Bray, 2010) reasonably well. ${ }^{12}$ The model correctly predicts that body size goes down during the early phase of industrialization. Eventually, however, the Industrial Revolution brings about a previously unseen increase in body size. At the end of the 20th century average male height is predicted to be 1.76 meters, a value that matches the actual height of 16 to 24 year old men in England in the year 2000 (NHS, 2011) as well as the height of men born 19761980 reported in Hatton et al. (2010). During the 21st century height is predicted to increase further until it settles down with overshooting behavior at its steady-state level of 1.82 when the economy approaches the balanced growth path.

Given the simple structure of the model, the growth rate of TFP in manufacturing coincides with growth of income per capita. As can be seen by the middle panel in Figure 4, income per capita exhibits accelerating growth from about 1850 onwards, whereas body size continues to decline until circa 1900. Hence, the model replicates the puzzling finding from the anthropometric history literature, that body size declines in England during a period of rising income, early in the Industrial revolution.

The last panel shows the predicted consumption of calories per capita. Since 1800 the trajectory is roughly consistent with the estimates of Floud et al. (2011) and the FAO (2012, data for

\footnotetext{
${ }^{12}$ We took from Komlos (1993) the data on height of 20 to 29 year old British soldiers. Komlos provides the data as index numbers. In order to compare with the Hatton et al. data we used conversion rate of an index number of 98.6 (indexed height in 1850) into absolute height of 1.66 meter (predicted height in 1850). Madsen et al. (2010) provided estimates of aggregate TFP in Britain on an annual basis obtained from growth accounting as Solow residuals. Naturally, there is huge fluctuation on annual TFP growth rates, which we smoothed by using 50 year moving averages as in Strulik (2011).
} 
1960- 2000). For the 18th century the trajectory lies above Floud et al.'s estimates and below Allen's (2005) estimate. The fit of the calorie trajectory could be improved by relaxing the assumption that the energy exchange rate stays constant and take into account technological progress in food processing, that is by imposing an increasing rate of energy extracted per unit of food. ${ }^{13}$

\section{Comparative Physiological Development and the Fertility Decline}

In this section we take a first pass at examining the key prediction of the model. Namely, that the timing of the fertility transition is an important determinant of contemporary cross-country differences in body size.

5.1. Model Predictions: Cross-Sectional Implications. The motivation for the present study is the desire to try to understand contemporary comparative physiological development. Hence, in an effort to study the models' implications in this regard, we begin by investigating the impact of the onset of the fertility transition on (average) body size today by way of numerical experiments. Specifically, we keep all the parameters values from the calibration above constant, and perturb the initial conditions for agricultural productivity and population size such that the fertility transition takes place (in most cases) later than in England. We then, for each simulation, record the year of the fertility transition and the predicted body size in $\mathrm{cm}$ of adult males in the year 2000 (i.e. the cohort born in 1975). Figure 5 shows the result. In countries where the fertility transition occurs during the mid 19th century, predicted body size a century and a half later is about $1.80 \mathrm{~m}$. In contrast, for latecomers that underwent the fertility decline, say in the 1920s, average body size is predicted to be about $1.70 \mathrm{~m}$.

According to Reher (2004), Sweden was the forerunner in terms of the fertility decline, seeing its onset in the late 1850's/ early 1860s; the latecomer in a European context was Portugal with the onset of the fertility decline occurring in the 1920s. According to Hatton and Bray (2010) the average size of Swedes born in 1980 was $180.4 \mathrm{~cm}$, with the comparable number being 172.3 for Portugal. Hence the model does a reasonably good job at capturing the range in body size across Europe, as of today, given plausible variation in the timing of the fertility transition.

\subsection{Regression Analysis.}

\footnotetext{
${ }^{13}$ In our numerical study we have not focused on the path for relative prices and sectoral shares because these aspects of the model are not original to the present study and discussed in detail by Strulik and Weisdorf (2008) who demonstrated that the fertility transition indeed is associated with rising relative prices of food provisions.
} 
Figure 5: Onset of Fertility Decline vs. Height of Adult Males in 2000

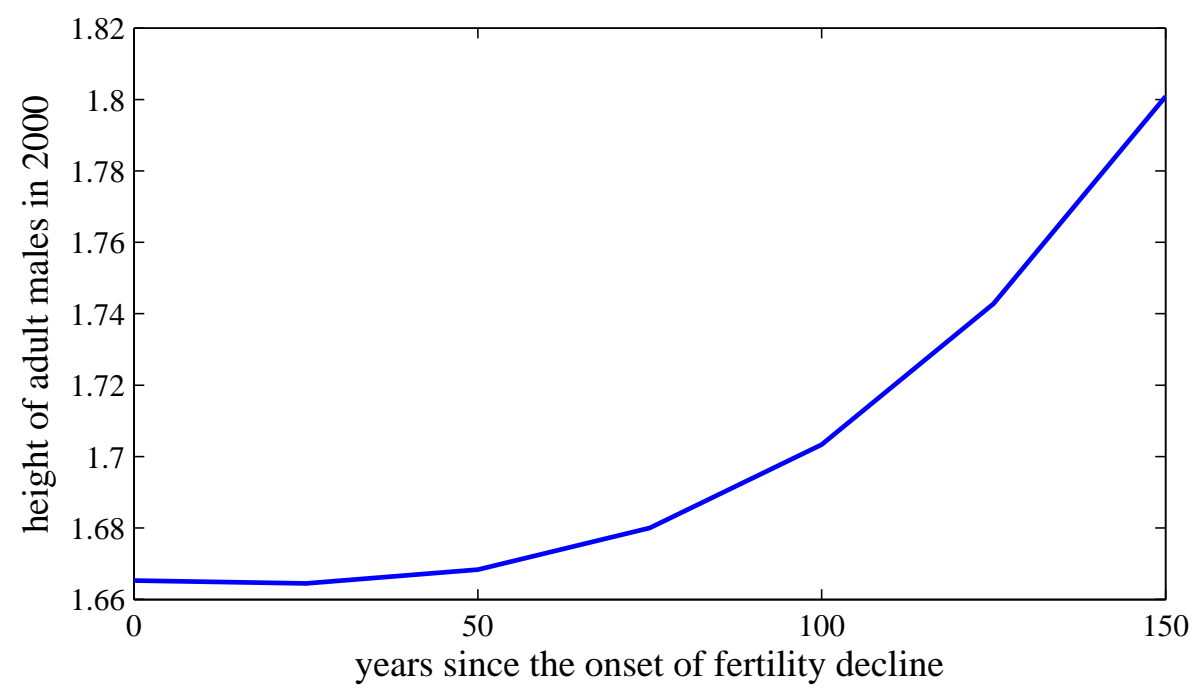

Parameters as for Figure 1. Variation in initial conditions of knowledge and population size in the year $0 \mathrm{AD}$. Year of fertility decline is the year (generation) after the year (generation) with maximum fertility.

5.2.1. Data. The key dependent variable is body size of females, measured in kg. From the point of view of the theoretical model, this is an ideal measure of body size. The data largely originates from the Demographic Health Surveys (DHS), and reflect surveys conducted around the year 2000. In addition, we obtained further data points for a set of European countries, as detailed in the appendix. These additional data are useful, as DHS mainly survey low or middle income countries.

The other central variable for the empirical analysis is the timing of the fertility transition. The study by Reher (2004) provides transition dates for a large number of countries. When we combine our data on body size and the timing of the fertility decline, we are left with 67 country observations. Figure 6 depicts a scatter plot of years since the transition (YST $=2000$ transition year) and body size circa 2000. Qualitatively the picture conforms with expectations: forerunners of the fertility transition are today populated by women of greater physiological size around the turn of the 21st century, in keeping with the theory. But at a more subtle level, it is clear that the model does not capture all details fully, as the mapping between the two variables is concave, rather than convex (cf. Figure 5). This subtle shortcoming of the model is also visible in Figure 4, where the model underestimates the speed at which body size rises right after the take-off. However, at the end of the period examined the model and the data "converge". From an empirical standpoint, then, the time series data and the cross-sectional data seem mutually 
Figure 6: Years Since the Fertility Decline and Body Size

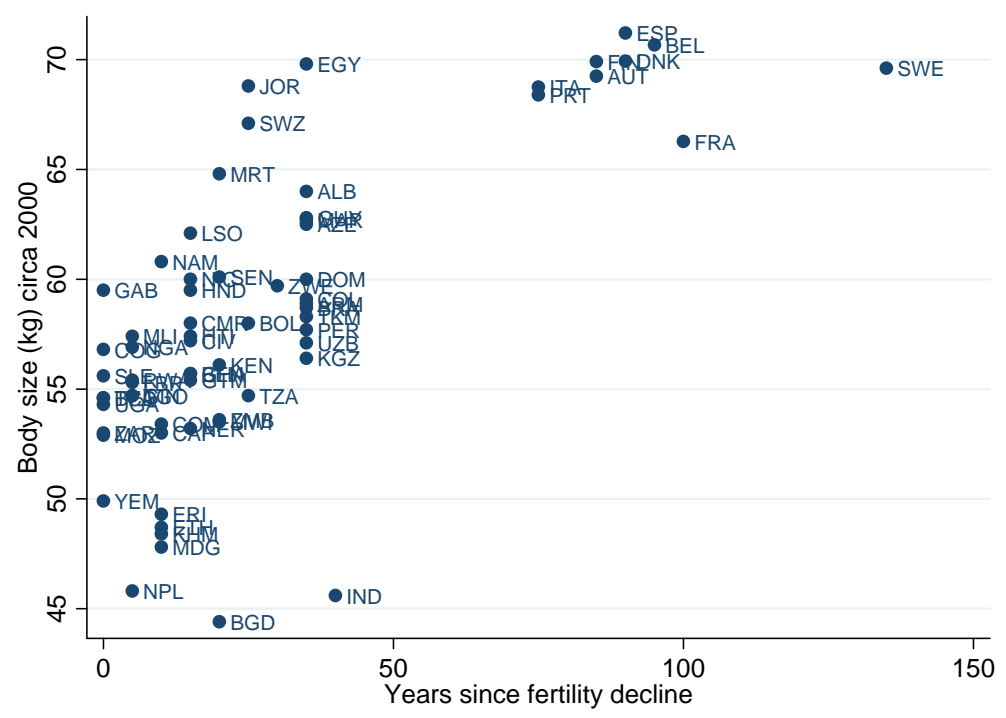

The figure shows years since fertility decline, defined as 2000 minus year of onset, versus current (ca.) body size (kg). The sample includes 67. See Appendix for details on data.

consistent. That is, during transition body size increases rapidly in the immediate aftermath of the transition, yet slows down as the economy matures. This would produce a concave mapping between YST and body size, as found in Figure 6. Hence, these patterns are consistent with the overall hypothesis: early take-off is linked to greater current body size.

5.2.2. Specification. The specification we take to the cross-section data has the following form:

$$
m_{i}=\beta \log Y S T_{i}+X_{i}^{\prime} \gamma+u_{i}
$$

where $X_{i}$ contains potential confounders (and a constant term), whereas $u_{i}$ is noise. YST enters $\log$ transformed to mimic the concave link observed in Figure $6{ }^{14}$

Reverse causality can obviously not account for a positive correlation between YST and current body size. But one may legitimately worry about omitted variables.

Hence, the first set of controls constitutes geographic determinants of average body size. The motivation is that, empirically, there appears to be a strong positive correlation between average

\footnotetext{
${ }^{14}$ Since countries that as of 2000 had not undergone the fertility transition are coded,by Reher (2004) as "2000" we employ the transformation $\log (1+Y S T)$ in order to keep as many countries in the sample as possible. In a previous version of the paper we employed a quadratic specification for $Y S T$, which leads to similar results. Notice that $m$ enters linearly on the left hand side. An alternative would be a log-log specification, with $\log (m)$ being the dependent variable, and the results are - qualitatively - very similar to those reported below, and available upon request.
} 
body size and distance to the equator. In biology and physical anthropology, this link (which holds across most mammalian species) is referred to as "Bergmann' rule", after Bergmann (1847). ${ }^{15}$ The most common interpretation of the "latitude gradient" is that it has appeared due to positive selection towards greater cold tolerance (e.g., James, 2010), and that bigger bodies are more cold tolerant (see e.g. Ruff, 1994). ${ }^{16}$ It is worth emphasizing that the model can elucidate the consequences of genetic changes in regards to cold tolerance. To see how, notice from the energy conservation equation (equation (2)) that it leaves no room for heat loss; heat loss is thus implicit in the parameters. Cold tolerance, or less heat loss, can conveniently be captured by a lower value for $b_{c}$. That is, we may capture genetic change towards cold tolerance as lower energy requirements to run and maintain cells in the body, due to reduced heat loss. Next, observe from Proposition 3 that if $b_{c}$ declines, body size increases at the steady state. Accordingly, if individuals residing in colder climate zones (away from the equator) have grown more cold tolerant we would expect them to be heavier as well, according to the theory developed above. As a consequence, we add several geographic variables to try to control for genetic adaptation: average frost days, distance to the equator, tropical area and continental fixed effects.

Another evolutionary theory holds, that the disease environment could prompt selective pressure, affecting body size (Migliano et al., 2007). The theory is that in high disease environments it is an advantage to reach sexual maturity early in life. But earlier sexual maturity comes at a cost of premature cessation of body growth. Hence, in areas with a "hostile" climate, the theory proposes, one would expect to see smaller bodies being selected. Naturally, the aforementioned climate variables may also act as controls for this channel. Since climate tends to be more hostile towards humans in the tropics (from the point of view of diseases), one would expect to see individuals near the equator to be smaller, ceteris paribus. In part this channel is therefore possibly covered by the geography variables above. But to capture the disease channel more specifically we also introduce malaria ecology in $X_{i} \cdot{ }^{17}$

\footnotetext{
${ }^{15}$ Evidece, in the context of the human species, is found in e.g. Roberts (1978), Ruff (1994), Katzmarzyk and Leonard (1998) and Gustavson \& Lindenfors (2009).

${ }^{16}$ The argument made in biology and anthropology is typically a geometric one; bigger bodies (measured by body mass $(\mathrm{kg})$ ) exhibits a smaller surface to volume ratio, which serves to limit heat loss. This is naturally an advantage if living in cold environments.

${ }^{17}$ Ideally one would of course like to have data on climate 50,000 or more years ago to better approximate the climate conditions that might have set the evolutionary processes in motion. In the present case we rely on the assumption that current climate conditions are sufficiently highly correlated, in a cross-country context, with past conditions to be a meaningful proxy.
} 
Next, we also introduce income per capita and child mortality around the year of birth of the cohorts captured by our data on body size. As noted above, body size is recorded around 2000. The DHS data stems from the maternal health module, which means that the women surveyed were between 15 and 49 years of age in 2000. As a result, we employ GDP per capita and mortality rates in 1980 as a proxy for childhood circumstances. While GDP per capita and mortality obviously are endogenous, we hope to limit the scope of bias by lagging them by 20 years compared to the year of observation of body size. ${ }^{18}$

Finally, since body size is not always measured exactly in 2000, we add a control for the year of observation. In addition, we add a dummy which takes on the value of 1 if the observation derives from DHS, and zero otherwise. In this manner we hope to eliminate any bias resulting from the different sources of the data on body size. All data sources are listed in the Data Appendix.

5.2.3. Results. Table 2 reports the results from our checks of the basic correlation depicted in Figure $6{ }^{19}$ In column 1 we study the link between YST, without any controls except for continental fixed effects, and our source controls. The visually obvious correlation from Figure 6 is reflected in a highly significant point estimate. Together with our continental controls, and source indicators, the model accounts for roughly $2 / 3$ of the variation body size. In the next five columns we add the climate controls sequentially, and together. The introduction of these variables does reduce the point estimate for YST somewhat, but it remains statistically significant. The climate controls are individually insignificant, but jointly significant (p-value of 0.09). In light of the obtained signs, this is consistent with the relevance of the evolutionary arguments laid out above.

In Columns 7-9 we add childhood environmental controls in the form of income and mortality. Both are individually significant (column 7 and 8), with signs that conform with expectations: higher income and lower mortality during childhood is associated with greater adult stature.

In Column 10 we add all of the controls at the same time. In the full specification we account for about $80 \%$ of the variation in body size. As can be seen, YST remains statistically

\footnotetext{
${ }^{18}$ One might also contemplate education as a determinant. But education of the parents cannot have any direct physiological impact on adult body size of the offspring; at most it can influence the more proximate determinants of the adult size of children: income and child health. Besides, its strong correlation with income and health is well known. As a result, education is not part of the control set on a priori grounds.

${ }^{19}$ As can be seen from the bottom part of the table we have 58 observations in our regressions, rather than 67 as in Figure 6, since we control the sample size to be the same in all columns. That way it is possible to assess the pure consequences of adding and removing confounders. The results are qualitatively unaffected by not doing so.
} 


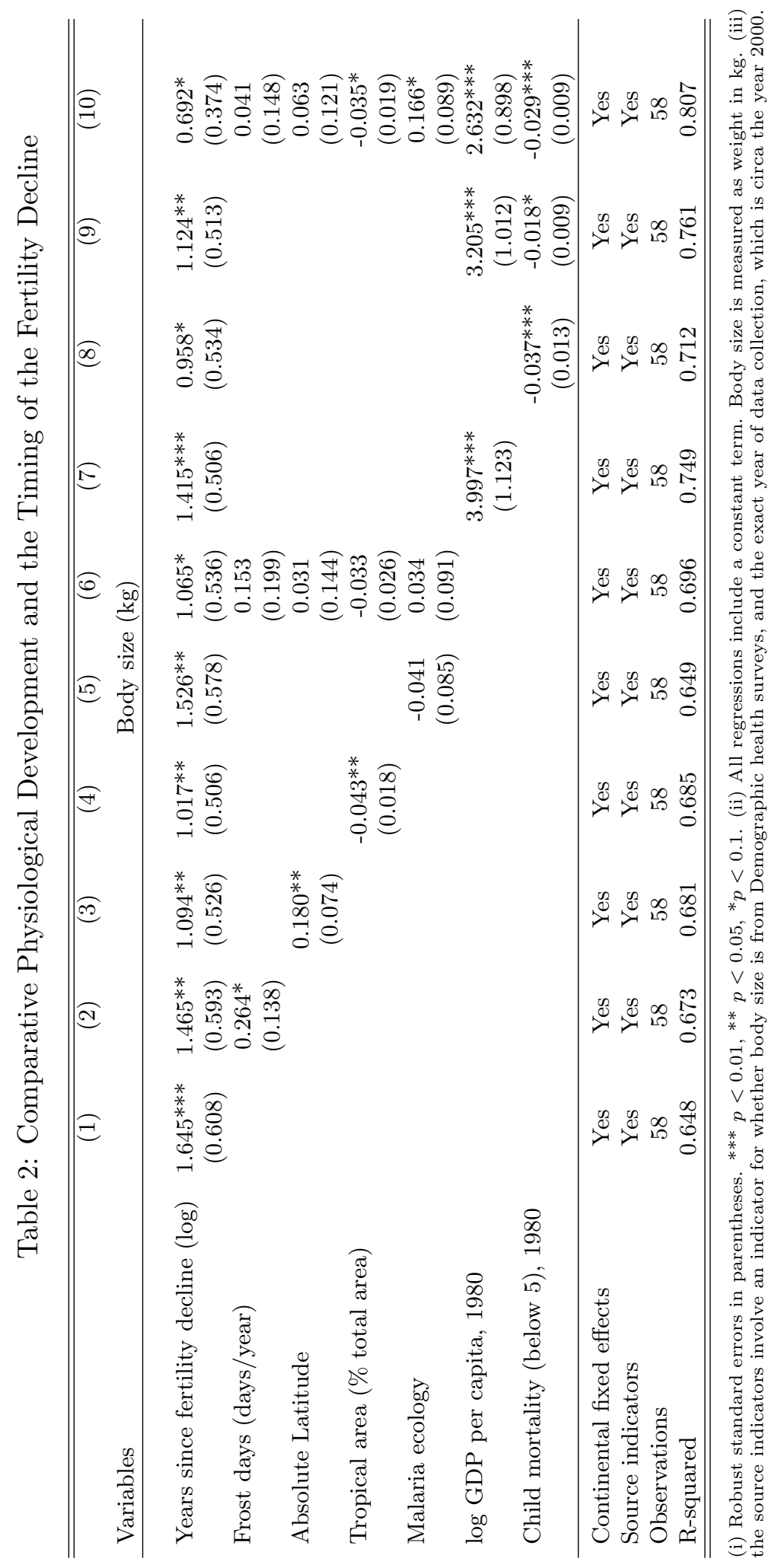


significant. Hence, even when we control rigorously for geography as well as income and mortality, YST remains a significant determinant of current differences in body size across the world. Interestingly, among the climate controls, the fraction of the country's area in the tropics also remain significant, despite the simultaneous control for income and mortality. Moreover, the three climate variables (frost, absolute latitude and tropical area) are jointly strongly significant $(\mathrm{p}$-value $=0.02)$

What is the economic significance of the estimates? In the data body size varies from about $46 \mathrm{~kg}$ (5th percentile) to roughly $70 \mathrm{~kg}$ (95th percentile). We shall refer to this as the "95/5 gap", and the question is how much of this gap may be attributable to YST. To provide an estimate, we observe that log YST varies by about $4.6 \log$ points (or, equivalently, YST varies by 95 years), moving from the 5 th to the 95 th percentile. If we then take the point estimate from column 10 at face value, the variation in YST can account for circa $13 \%$ of the "95/5 gap" in average body mass $\left(=\left(0.7^{*} 4.6\right) /(70-46)\right)$.

One could argue, however, that this estimate is too conservative. In the full specification we condition on income per capita and mortality during childhood. But these are partly outcomes of the fertility transition. More specifically, consider income per capita. In the present model the fertility transition stimulates economic growth, by alleviating population pressure on scarce natural resources, and thereby affects the level of income per capita positively. In this sense, income per capita may constitute a "bad control" (Angrist and Pischke, 2009, Ch. 3). ${ }^{20}$ Next, consider mortality. Mortality is obviously not captured explicity by the model (or rather, it is exogenously given: two periods of life), but if the fertility transition in practise stimulates investment in nutrition, as our theory predicts, and nutrition reduces mortality (e.g., Fogel, 1994), then the timing of the fertility transition may well be viewed as partly responsible for the current level of mortality as well.

Hence, suppose we instead rely on the reduced form point estimate from column 1; i.e., where we have no additional controls except from continental fixed effects. This leads to the conclusion that about $30 \%$ of the "95/5 gap" in body size may be ascribed to the timing of the fertility transition $\left(=\left(1.6^{*} 4.6\right) /(70-46)\right)$.

\footnotetext{
${ }^{20}$ In the present context we have ignored human capital in the sense of education, in an effort to focus on the novel trade-off between size and number. But in unified growth models where human capital is present, the impact from the fertility transition on the growth process becomes much more profound. The fertility transition allows for systematic investments in human capital thereby stimulating growth directly, and indirectly via technological change; see e.g. Galor and Weil (2000), Galor and Moav (2002) and Lucas (2002).
} 
This result may well overstate the influence from the fertility transition, even if the current level of income and mortality (or rather, the levels around the time of birth) were fully explained by the fertility transition. The reason is that genetic differences may explain some of the differences in contemporary body size, and could at the same time be correlated with the timing of the fertility transition. Since geography is assigned a special role in capturing genetic variation this seems like a very real risk. Hence, if we instead employ the results from column 6 , where we control rigourously for geography, we conclude that the fertility transition accounts for about $20 \%$ of the "95/5 gap" $(=4.6 /(70-46))$.

The bottom line is that "history" appears to hold considerable explanatory power vis-á-vis global inequality in physiological development around the year 2000. According to the above estimates one can argue that the timing of the fertility transition accounts for somewhere between $13 \%$ and $30 \%$ of the globally observed body size variation. The remaining variation can then be viewed as due to genetic differences, or differences in income and mortality that are orthogonal to the timing of the fertility transition.

\section{Conclusion}

In the present study we have taken on the task of understanding the global variation in physiological development, measured by human body size. Understanding physiological development is important, as stature appears to be causally related to many proximate sources of welfare: education, longevity and even self-reported happiness. Concretely, we advance the hypothesis that the current variation in physiological development has important historical roots in the differential timing of the fertility transition.

The proposed mechanism behind the take-off is that differential technological progress across sectors eventually led to an increasing price of provisions, triggering a quantity-quality trade-off according to which family size shrunk, and nutrition per child increased. As fertility declined, growth took off and average body size started increasing secularly.

From an empirical standpoint the model provides two contributions. First, it provides one explanation for the puzzling U-shaped path of average body size during industrialization. In the theory developed above, this path reflects the "size-number" trade-off: average body size should therefore decline, and then venture on to a positive growth path, as fertility first rises 
and eventually declines during the fertility transition. Hence, declining average body size is reconcilable with rising income per capita during the take-off.

Second, the theory predicts that the relative timing of the fertility transition is a significant determinant of global differences in physiological stature: individuals living in countries that were forerunners to the fertility transition should (on average) be bigger today. A first pass look at the data seems to confirm this prediction: conditional on contemporary income and mortality (nutrition and disease environment during childhood), as well as geography confounders, the timing of the fertility transition remains a significant determinant of body size. We find that between $13 \%$ and $30 \%$ of observed differences in body size plausibly can be accounted for by variation in the timing of the take off. Hence, simply put: "the West is taller than the rest" in part because it went through the fertility transition earlier.

From the point of view of the present study, several future lines of research may be fruitful. First, with regards to the advanced hypothesis stronger evidence is needed in favor of the link between the timing of the fertility transition and current body size. In spite of our best efforts to control for likely confounders, doubt may legitimately linger as for identification. Second, as observed above, our theoretical model is not able to fully account - quantitatively - for the apparent rapid acceleration in body growth in the immediate aftermath of the fertility transition. Third, many different hypotheses have been advanced in the anthropometric economic history literature regarding the long-run evolution of human body size. It remains an open question whether these alternative accounts simultaneously are consistent with observed changes in fertility, sectoral allocations and income. But, to a first approximation, it would appear that a theory involving changing relative prices of provisions, in the presence of a size-number quantity-quality trade-off, is.

Finally, the present study has not addressed the potential role played by persistent, historical, differences in physiology in affecting contemporary economic development. In a companion paper (Dalgaard and Strulik, 2014) we argue that societies that historically were inhabited by physiologically bigger people, as a consequences of natural selection, have experienced the timing of the take-off to sustained economic growth relatively earlier. Hence, a more balanced view than what we have been able to espouse in the present paper is that physiological development very likely is both consequence and a driver of economic development in the long run. 
APPENDIX

Proof of Proposition 5. Let $g_{t}^{x}$ denote the growth rate of a variable $x_{t}$ and $g^{x}$ the associated balanced growth rate. Lagging (24) one period we observe:

$$
1+g_{t}^{p}=\frac{\left(1+g_{t}^{Q}\right)\left(1+g_{t}^{L}\right)^{1-\alpha}}{1+g_{t}^{A}} .
$$

As usual a balanced growth path is defined by constant rates of growth and constant sectoral labor shares. In addition, balanced growth requires that the relative price of food is constant to ensure that fertility and body size are constant. This requires that

$$
\left(1+g^{A}\right)=\left(1+g^{Q}\right)\left(1+g^{L}\right)^{1-\alpha}
$$

Imposing $g_{p}=0$ in (A.1) and inserting (A.2) we obtain that constant productivity growth in both sectors requires that

$$
\left(1+g^{A}\right)^{\xi-1}=\left(1+g^{L}\right)^{\alpha \xi}, \quad\left(1+g^{Q}\right)^{\phi-1}=\left(1+g^{L}\right)^{\phi} .
$$

Inserting (A.3) into (A.2) provides the condition

$$
\left(1+g^{L}\right)^{\phi /(\phi-1)}\left(1+g^{L}\right)^{1-\alpha}=\left(1+g^{L}\right)^{\alpha \xi /(1-\xi)} .
$$

From this we infer that balanced growth requires either no population growth or the knife edge condition $\phi /(1-\phi)+1-\alpha=\alpha \xi /(1-\xi)$. Ignoring the degenerate knife-edge case, we establish uniqueness of the stationary solution by assuming that $\phi /(1-\phi)+1-\alpha<\alpha \xi /(1-\xi)$. This rules out all unbalanced trajectories (along which the population is exploding or permanently shrinking) as long-run solutions. The balanced growth path remains as the only feasible solution.

The Reduced Form Correlation between Income and Body Size. In the model there is no direct (partial) effect of income on fertility and offspring nutrition. Yet, it is worth noting that the model does provide a clear income/body size correlation via prices; from an empirical standpoint GDP per capita may then serve as a stand-in for the relative price, as noted in Section 5 .

To see this, Figure A.1 shows the link between income, body size and fertility, according to the simulation conducted in Section 4. As can be seen, body size and income is positively correlated from the time of the take-off and until today. 
Figure A1: Stature and Fertility and Income: 1700 - 2000

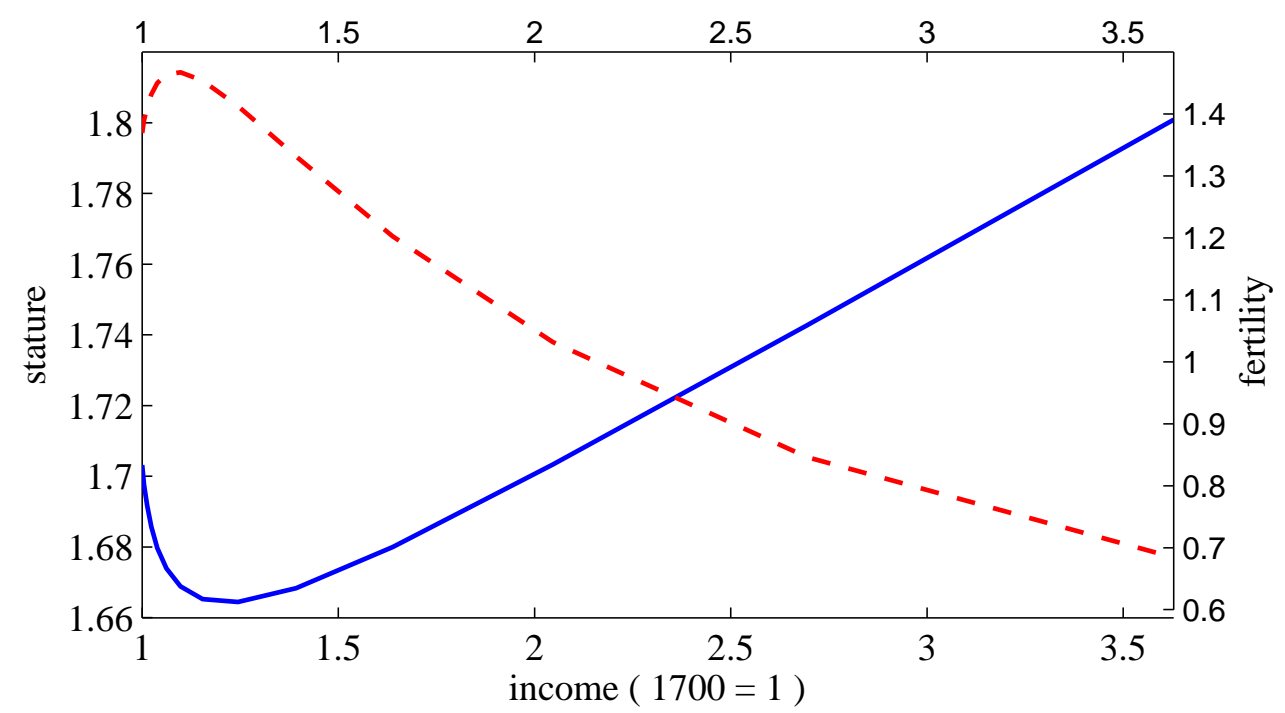

Blue solid line: stature (left axis). Red dashed line: fertility (right axis). Income per capita $(Q)$ is normalized such that $Q(1700)=1$. Parameters as for Figure 1.

\section{Data Appendix.}

Panel data set.

- The data on height is from Hatton and Bray (2010), who augment the work of Garcia and Quinta-Domeque (2007). Data consists mainly of army recruits of about 20 years of age

- The data on GDP per capita is due to Angus Maddison, http:// www.ggdc.net/ MADDISON/ oriindex.htm

- The data on vital rates (Crude birth rate and crude death rate) is taken from Reher (2004).

- The dummy WWI takes on the value 1 in the (two) periods encapsulating 1914-1918; WWII is the same for 1940-45. Finally Great Depression involves the years 1929-1935.

There is a slight inconsistency between the height data and the data on vital rates. Height data comes as five year observations with the demarcations 1856-1860, 1861-1865 etc, whereas the vital rates come in the time undervalues 1855-59, 1860-1864 etc. In the panel exercise this difference is finessed by assuming that average vital rates for 1855-59 (etc) are identical to those of 1856-1860 (etc). While unattractive, it seems doubtful 1 that this minute mismatch influences the results. 
Cross Country data. Data on the timing of the fertility decline is due to Reher (2004)

For most of the countries in the sample data on female weight is from Demographic Health Surveys (DHS); extracted by StatCompiler (http://www.statcompiler.com/ ) on 24.1.2012. Survey's close to the year 2000 were selected. Since mothers are singled out in the DHS, implying women are in the age interval 15-49; the sampled individuals were therefore born in 1985 or earlier.

We supplemented these data by data on height for 9 European countries. The data also concerns women, born in 1980. The source is Garcia and Quinta-Domeque (2007), supplemented by Herpin (2003, p. 73) for France. In the latter case the data concerns 20-29 year-olds, observed in 2001 (implying they were born around 1980). The French figure is adjusted down by $0.8 \mathrm{~cm}$ to correct for self reporting (see Hatton and Bray, 2010). Finally, in order to generate data on weight we employed data on female BMI (in 2000) from the study by Finucane et al. (2011, Supplementary material p. $60 \mathrm{ff}$ ). Using these BMI numbers along with the height data (for the 9 country European sample), weight data is constructed using the formula $B M I=w / h^{2}$ (height in $\mathrm{m}$ ).

Geography: Continent dummies (Africa, Asia, North America, South America, Europe, Oceania); Tropics and latitude. Source: Nunn and Puga (2010); Malaria Ecology: Sachs, 2003.

GDP per capita and mortality, 1980: World development indicators (available online at: http://data.worldbank.org/)

Frost (average of days per year): Source: Masters and McMillan (2001). 


\section{REFERENCES}

Allen, R.C., 2005. English and Welsh agriculture, 1300-1850: outputs, inputs, and income, Working Paper, Nuffield College, Oxford.

Anand, S. and Sen, A.K., 1997. Concepts of human development and poverty: a multidimensional perspective, Human Development Papers, United Nations Development Programme, New York.

Angrist, J. and J-S. Pischke, 2009. Mostly Harmless Econometrics. Princeton University Press.

Ashraf, Q., and Galor, O. 2011. Dynamics and stagnation in the Malthusian epoch. American Economic Review 101, 2003-41.

Becker, G., 1960. An economic analysis of fertility. In: Demographic and economic change in developed countries. Conference of the Universities-National Bureau Committee for Economic Research, a Report of the National Bureau of Economic Research. Princeton University Press, Princeton, NJ, pp 209-240

Bergmann, C., 1847. Ueber die verhältnisse der wärmeökonomie der thiere zu ihrer grösse. Gottinger Studien 3, 595-708.

Boyer, G.R., 2004. Living standards, 1860-1939. Chapter 11 in R. Floud and P. Johnson (eds): The Cambridge Economic History of Modern Britain, Vol II: Economic Maturity, 1860-1939. Cambridge University Press.

Caldwell, J. C. , 2004. Social upheaval and fertility decline. Journal of Family History 29, $382-406$

Carrieri, V. and Paola, M.D., 2012. Height and subjective well-being in Italy. Forthcoming: Economics and Human Biology

Case, A. and Paxson, C., 2008. Height, health, and cognitive function at older ages. American Economic Review,98, 463-467.

Case, A., Paxson, C., and Islam, M., 2009. Making sense of the labor market height premium: Evidence from the British Household Panel Survey. Economics Letters,102, 174-176 
Cinnirella, F., Piopiunik, M., and Winter, J., 2011. Why does height matter for educational attainment? Evidence from German children. Economics and human biology, 9, 407-18

Charnov, E.L., 1991. Evolution of life history variation among female mammals. Proceedings of the National Academy of Sciences of the United States of America 88, 1134-1137.

Charnov, E.L., 1993. Life History Invariants, Oxford University Press, Oxford.

Charnov, E.L. and S.K.M. Ernest, 2006. The offspring - size / clutch - size trade-off in mammals. The American Naturalist 167, 578-82.

Clark, G., 2007. Farewell to Alms: A Brief Economic History of the World, Princeton University Press.

Clark, G., 2007b. What made Britannia great? How much of the rise of Britain to world dominance by 1850 does the Industrial Revolution explain? in: Hatton, T.J., O’Rourke, K.H. and Taylor, A.M. (eds.) The New Comparative Economic History: Essays in Honor of Jeffrey G. Williamson, MIT Press, 33-57.

Cole, T.J., 2000, Secular trends in growth, Proceedings of the Nutrition Society 59, 317-324.

Dalgaard, C-J. and H. Strulik, 2011. A physiological foundation for the nutrition-based efficiency wage model. Oxford Economic Papers 63, 232-253.

Dalgaard, C-J. and H. Strulik, 2015. The Physiological Foundation of the Wealth of Nations. Journal of Economic Growth 20, 37-73

Dalgaard, C-J. and H. Strulik, 2014. Physiological Constraints and Comparative Development. Discussion Paper 14-21, University of Copenhagen.

Deaton, A. and Arora, R., 2009. Life at the top: The benefits of height. NBER working paper 15090.

FAO, 2012, FAOSTAT, Food Balance Sheets (www.http://faostat.fao.org).

Floud, R., Fogel, R.W., Harris, B., and Hong, S.C., 2011. The Changing Body: Health, Nutrition, and Human Development in the Western World since 1700, Cambridge University Press, Cambridge. 
Foellmi, R. and Zweimueller, J., 2006. Income distribution and demand-induced innovations. Review of Economic Studies 73, 941-960.

Foellmi, R. and Zweimueller, J., 2008. Structural change, Engel's consumption cycles and Kaldors facts of economic growth. Journal of Monetary Economics 55, 1317-1328.

Fogel, R.W., 1994., Economic growth, population theory, and physiology: The bearing of longterm processes on the making of economic policy. American Economic Review 84, 369-395.

Finucane, M.M , Stevens, G.A., Cowan, M.J., Danaei, G., Lin, J.K., Paciorek, C.J., Singh, G.M., Gutierrez, H.R., Bahalim, A.N., Farzadfar, F., Riley, L.M., and Ezzati, M., 2011. National, regional, and global trends in body-mass index since 1980: systematic analysis of health examination surveys and epidemiological studies with 960 country-years and 91 million participants. Lancet, 377, 557-67

Frankenberg, E., Smith, J.P., and Thomas, D., 2003. Economic shocks, wealth, and welfare. Journal of Human Resources 38, 280-32.

Galor, O., 2006. From stagnation to growth: Unified growth theory, in P. Aghion and S. Durlauf (eds.) Handbook of Economic Growth, North Holland, Amsterdam.

Hatton, T.J. and Bray, B.E., 2010. Long run trends in the heights of European men, 19th-20th centuries. Economics \& Human Biology 8, 405-413.

Kleiber, M., 1932. Body size and metabolism. Hilgardia 6, 315-353.

Koepke, N. and Baten, j., 2005. The biological standard of living in Europe during the last two millennia. European Review of Economic History 9, 61-95.

Komlos, J., 1993. The secular trend in the biological standard of living in the United Kingdom 1730-1860. Economic History Review, 46, 115-44.

Komlos, J., 1998. Shrinking in a growing economy? The mystery of physical stature during the Industrial Revolution. Journal of Economic History 58, 779-802.

Kongsamut, P., Rebelo, S., and Xie, D., 2001. Beyond balanced growth. Review of Economic Studies 68, 869-882. 
Kuh, D.L. and M. Wadsworth M, 1989, Parental height: childhood environment and subsequent adult height in a national birth cohort, International Journal of Epidemiology 18, 663-668.

Kunitz, S., 1987. Making a long story short: A note on mens height and mortality in England from the first through the nineteenth centuries. Medical History 31, 269-80.

Lee, R., 1990. The demographic response to economic crisis in historical and contemporary populations. Population Bulletin of the United Nations 29, 1-15.

Madsen, J.B., Ang, J.B., and Banerjee, R., 2010. Four centuries of British economic growth: the roles of technology and population. Journal of Economic Growth 15, 1-28.

Maslow A., 1943. A theory of human motivation. Psychological Review 50, 370-96.

Masters, W.A. and McMillan, M.S., 2001. Climate and scale in economic growth. Journal of Economic Growth 6, 167-186.

Migliano, A.B., Vinicius, L., and Lahr, M.M., 2007. Life history trade-offs explain the evolution of human pygmies. Proceedings of the National Academy of Sciences 104, 20216-20219 .

NHS, 2011. Health Survey for England 2010: Trend Tables, NHS Information Centre.

Nunn, N. and Puga, D., 2012. Ruggedness: The blessing of bad geography in Africa. Review of Economics and Statistics 94, 20-36.

Prentice, A.M. and Whitehead, R.G., 1987. The energetics of human reproduction. Symposia of the Zoological Society of London 75, 275-304.

Reher, D. S., 2004. The demographic transition revisited as a global process. Population Space and Place 10, 19-42.

Ruff, C., 2002. Variation in human body size and shape. Annual Review of Anthropology 31, $211-23$.

Sachs, J., 2003. Institutions don’t rule: Direct effects of geography on per capita income. NBER working paper 9490 .

Sadurkis, A., Kabir, N., Wagner, J., Forsum, E., 1988. Energy metabolism, body composition, and milk production in healthy Swedish woman during lactation. American Journal of Clinical Nutrition 48, 44-49. 
Schneider, R., 1996. Historical note on height and parental consumption decisions. Economics Letters 50, 279-83.

Schultz, T., 2002. Wage gains associated with height as a form of health human capital. The American Economic Review 92, 349-353.

Sharp, P., H. Strulik and J. Weisdorf, 2012. The determinants of income in a Malthusian equilibrium. Journal of Development Economics 97, 112-117

Silventoinen, K., 2003, Determinants of variation in adult body height, Journal of Biosocial Science 35, 263-285.

Steckel, R., 2009. Heights and human welfare: Recent developments and new directions. Explorations in Economic History 46, 1-23.

Stillman, S. and Thomas, D., 2008. Nutritional status during an economic crisis: Evidence from Russia. Economic Journal 118, 1385-1417.

Strulik, H., 2011. Knowledge and growth in the very long run. University of Hannover, Discussion Paper 459.

Strulik, H. and Weisdorf, J., 2008. Population, food, and knowledge: a simple unified growth theory. Journal of Economic Growth 13, 195-216.

Strulik, H. and Weisdorf, J., 2012. How child costs and survival shaped the Industrial Revolution and the demographic transition, Macroeconomic Dynamics, forthcoming.

Tay, L and Diener, E., 2011. Needs and subjective well-being around the world. Journal of Personality and Social Psychology 101, 354-365.

Vollrath, D., 2009. The dual economy in long-run development. Journal of Economic Growth $14,287-312$.

Walker R., M. Gurven, O. Burger and M.J. Hamilton, 2008, The trade-off between number and size of offspring in humans and other primates, Proceedings of the Royal Society 275, 827-33.

Weir, D.R., 1993. Parental consumption decisions and child health during the early French fertility decline: 1790-1914. Journal of Economic History 53, 259-74. 
Weisdorf, J., 2008. Malthus revisited: Fertility decision making based on quasi-linear preferences. Economics Letters 99, 127-130.

West G.B., Brown, J.H., and Enquist, B.J., 1997. A general model of the origin of allometric scaling laws in biology. Science 276, 122-26.

West G.B., Brown, J.H., and Enquist, B.J., 2001. A general model of ontogenetic growth, Nature $413,628-31$.

World Health Organisation, 2006. WHO child growth standards and the identification of severe acute malnutrition in infants and children, http://www.who.int/childgrowth/standards/cht_wfa_girls_p_6_2.pdfl.

Wrigley, E.A., and Schofield, R.S., 1989. The Population History of England 1541-1871. Edward Arnold, London. 